\title{
¿Un bicentenario ambientalmente sostenible?
}

\author{
Carmen Alexa Roldán-Chacón y Vilma Peña-Vargas *
}

Los seres humanos están hechos para relacionarse. Los ojos, la piel, la lengua, los oídos y las fosas nasales, son todos ellos puertas por las que el cuerpo se nutre de cuanto le rodea. Este paisaje de voces indescifrables, cuerpos emplumados, cornamentas y corrientes saltarinas; estas sombras vivas constituyen nuestra familia, los seres con los que estamos emparentados, con los que compartimos esfuerzos, sufrimientos y celebraciones.

— David Abram ${ }^{1}$

\section{Resumen}

El artículo $^{2}$ explora el tema ambiental desde un enfoque de la sostenibilidad a propósito del bicentenario de Costa Rica. Desde una visión crítica y más allá de una enunciación de los problemas ambientales que padece la sociedad, se hace un llamado urgente a cambiar la actitud personal, institucional y nacional para comprender que la humanidad está dentro de una red vital interconectada que la sitúa como la especie responsable de la catástrofe pero también la especie decisiva para la transformación.

La investigación recorre más de 200 años de la historia ambiental y rescata algunos elementos, para concluir que así como ha habido aciertos, se han tomado decisiones que atentan contra la seguridad en materia ambiental. La idea no es continuar con los lamentos o búsqueda de culpables, se trata de asumir responsabilidades y volver al camino de la Costa Rica sostenible que está en nuestro imaginario y, por lo tanto, que sí es posible.

Palabras clave: Desarrollo, derecho a un ambiente sano, educación ambiental, políticas e instrumentos ambientales, responsabilidad social.

* Las autoras son doctoras en Educación con énfasis en mediación pedagógica. Roldán-Chacón (https://orcid.org/0000-0002-0894-7093) es bióloga y Peña-Vargas (https://orcid.org/0000-0001-7565-0911) es comunicadora. Ambas ambientalistas y creyentes de que vivir es aprender.

\footnotetext{
${ }^{1}$ David Abram, La magia de los sentidos (Barcelona: Editorial Kairós, 2000), 9.

${ }^{2}$ Aprobado por el comité editorial de la Revista Espiga en sesión del 14 de mayo de 2021. La sección en que se publica no es arbitrada mediante el proceso de pares.
} 


\section{Introducción}

El 5 de febrero de 2021, uno de tantos días de noticias ambientales, el periódico $L a$ República publicó la amarga noticia de que en Costa Rica mueren 250000 abejas diariamente; al año, la cifra suma más de 92 millones $^{3}$. Este reportaje sorprende, no solo por el número de especímenes, sino por el impacto que representa estas muertes, porque las abejas participan en el mantenimiento de redes alimentarias, la polinización de árboles, la producción de miel, de alimentos, de medicamentos o de cosméticos. La pregunta es ¿Cuántas personas notaron o se preocuparon por el riesgo de esta pérdida para la sociedad? O bien ¿Qué estará sucediendo con las 800 especies de abejas, no solo las de interés comercial?

Igual que con las abejas, a lo largo de más de 200 años se ha venido perdiendo el patrimonio biológico por acciones humanas, entre ellas, la contaminación de muchos tipos, la destrucción de hábitats, introducción de especies, eliminación de especies nativas y urbanización. Ha habido decisiones oportunas que en algunos momentos han brindado esperanza a los defensores de la vida, pero en muchas ocasiones, dichos logros han sido invisibilizados o masacrados con acciones de orden económico o por inconciencia.

Costa Rica continúa en constante dualidad, tal parece que no se tiene una imagen clara de lo que se aspira en materia ambiental. En diferentes períodos se ha añadido parches que suman al logro de un desarrollo ambientalmente sostenible, pero estos parches no cubren la superficie, porque la meta de un ambiente sano y ecológicamente equilibrado no es la que guía las decisiones diarias de la mayoría de personas u organizaciones. Tampoco, debería ser solamente una meta de un gobierno de turno, sino la aspiración y el compromiso de cada habitante de este país y la obligación de cada visitante que se acoge.

La huella ecológica del costarricense es insostenible, ya que representa $8 \%$ más de lo que el territorio es capaz de reponer. Agua, energía, biomasa, cada uno de los productos que consumimos diariamente requiere cierta cantidad de recursos limitados para su producción y, tarde o temprano, se convertirán en un residuo más ${ }^{4}$.

La intención de este artículo es despertar emociones y motivar a la reflexión sobre la posición y actuación humana en el deterioro de la naturaleza ${ }^{5}$. No es de interés realizar un detallado recuento de problemas ambientales ni enfocarse en un período gubernamental específico porque cada cuatro años se tendría que hablar de debilidades, menores o mayores, con datos, más o menos imprecisos, sino enfocarse en la continuidad de daño ambiental.

\footnotetext{
${ }^{3}$ Jeffrey Garza, «Costa Rica desaprovecha su potencial en apicultura», La República, 5 de febrero de 2021, acceso: 22 de mayo de 2021, https://www.larepublica.net/noticia/costa-rica-desaprovecha-supotencial-en-apicultura. El artículo en mención es referente a Costa Rica y al letal uso de agro venenos como causante de dichas extinciones. La extinción de las abejas también se asocia a la posible extinción humana. Como esta, son muchas las llamadas de atención que hace la Madre Tierra y que pasan desapercibidas, porque se es incapaz de ligar la vida humana con la de estas sencillas y habilidosas criaturas.

${ }^{4}$ Katzy O'neal Coto, «El problema ambiental más grave de Costa Rica es el consumo», acceso: 20 de mayo de 2021, https://www.ucr.ac.cr/noticias/2019/07/16/el-problema-ambiental-mas-grave-en-costarica-es-el-consumo.html

${ }^{5}$ En este artículo, biodiversidad y naturaleza se utilizan como sinónimos. La biodiversidad es la diversidad biológica, constituida por ecosistemas, especies y genes.
} 
Luego de la lectura de publicaciones diversas sobre el estado de situación, se llega a concluir que Costa Rica no ha consolidado una cultura ambiental ni una visión compartida sobre un desarrollo que no atente contra el equilibrio ecológico y la sanidad ambiental. No se cuenta con una lista de chequeo incorporada internamente que brinde coherencia entre el sentir, el pensar y el hacer, de tal forma que se pueda rechazar o aceptar rápidamente acciones contrarias a la salud. Muchas personas carecen de «conciencia» ${ }^{6} \mathrm{y}$, lo peor, preocupa pensar en cuántas personas estarán en «coma ambiental», en un sueño profundo del que tendrían que despertar, lo cual no asegura que decidan cambiar o mejorar.

En procura de dar el derecho a la duda, no juzgar hasta que se pruebe lo contrario, la reiterada agresión al ambiente se asienta en la actuación de personas y grupos sociales que parecen estar desconectados de la red de la vida, que les falta conocimiento sobre su «realidad» y el impacto de sus actos, que están faltos de capacidad para reconocer la relación entre actuaciones y el deterioro ambiental, o bien, que no les interesa cambiar porque su meta es el dinero y el tenerlo constituye la razón de su existencia.

Los principales actores y actrices promotores del daño, en cualquier época histórica, son quienes anhelan aumentar su poder adquisitivo y su poder material. El respeto por la vida, en cualquiera de sus formas, no aplica para estas personas. Pero, el trabajo de quienes codician no sería posible sin quienes acuerpan sus intenciones o sin aquellas personas que se pliegan a sus intereses, dada su aparente indefensión e interés por satisfacer necesidades, particularmente necesidades básicas. En este punto se podría preguntar ¿Cuál es la respuesta personal, o la de la organización en que se trabaja, ante las acciones que atentan contra la naturaleza, inocente, funcional, cómoda, o indiferente?

En estas apreciaciones, se disculpa a aquellos grupos humanos víctimas de la ignorancia, de la codicia y avaricia, que viven sumidos en una profunda pobreza material y carentes de medios para educarse y mejorar sus condiciones de vida. Se considera factible salir de esta condición, pero se es conscientes de que no es sencillo.

En el discurso oficial de la conmemoración del bicentenario, el 26 de febrero del 2021, se indicó:

Conmemorar el bicentenario de nuestra independencia, es celebrar que, a lo largo de 200 años, las y los costarricenses nos hemos dedicado a construir, en libertad, un país que hoy es ejemplo para el mundo por el compromiso de su pueblo, con la democracia, la paz, la solidaridad, los derechos humanos y el ambiente. ${ }^{7}$

\footnotetext{
${ }^{6}$ Conciencia. Conocimiento claro y reflexivo de la realidad («Aquí hay poca conciencia ecológica»). Consciencia. Capacidad de reconocer la realidad circundante («Por fin recobró la conciencia»). Ambas definiciones textuales del Diccionario de la Real Academia Española. https://www.rae.es/ ${ }^{7}$ Archivo Nacional de Costa Rica, «Costa Rica comienza el camino de la conmemoración de sus 200 años de independencia», acceso: 16 de mayo de 2021, https://www.archivonacional.go.cr/index.php/component/content/article/128-noticias/246-costa-ricacomienza-el-camino-de-la-conmemoracion-de-sus-200-anos-de-independencia?temid=437
} 
Las palabras del señor presidente, positivas y esperanzadoras, resultan un tanto contradictorias. Al observar situaciones que acontecen a lo largo de la historia, entre ellas, la imposición o apropiación de modelos de desarrollo, lineamientos macroeconómicos adoptados, la dependencia de recursos aportados por organizaciones internacionales, las cifras del estado de la biodiversidad, la cantidad y tipo de ilícitos ambientales, el aumento o innovación en los motores de daño ambiental, las cambiantes prioridades presupuestarias de los gobiernos y poderes $\mathrm{y}$, muy especialmente, la ausencia de un mapa de ruta clara que a lo largo de los años tenga como eje fundamental en la toma de decisiones, el logro de un ambiente sano y ecológicamente equilibrado, entonces se duda de que exista una independencia como la deseada.

Aun cuando con orgullo se deben conmemorar los logros alcanzados, se continúa siendo dependientes de las decisiones de otros y, lo que es peor, se sigue emulando valores y acciones propias de modelos criticables que han impactado severamente el ambiente, con actividades que se repiten en algunos países donde tienen operaciones. Con lo complejo que es el planeta y los sistemas que la especie humana impone, resulta difícil escapar a estas cadenas.

Se aclara el no estar hablando del $100 \%$ de las personas ni del $100 \%$ de las empresas, organizaciones o instituciones, se es conscientes de que hay quienes trabajan, sin interés personal alguno, procurando construir un país mejor y aportar a la sostenibilidad ambiental, en ocasiones son favorecidas con la escucha y apoyados, en otros momentos son silenciados, cuestionados, irrespetados $\mathrm{o}$ hasta invisibilizados. Reconocer los sentidos o sinsentidos no es sencillo, siempre política o socialmente aceptado.

Se puede afirmar que la libertad es condicional, en función de los compromisos creados por propios y externos; para ejercer libertad, se requiere de independencia, pero se tiene una independencia frenada o reducida por causa de miembros de una sociedad que sustentan paradigmas económicos no sostenibles ambientalmente, o bien codiciosos, avaros, inconscientes u oportunistas que luego de agotar un sitio se mueven a otro que puedan seguir utilizando. La independencia está afectada por personas que desconocen o no quieren reconocer la importancia de la conservación de la biodiversidad, para las presentes y futuras generaciones, pues siguen pensando en conceptos antiguos como «recursos renovables» o creen que la tecnología resuelve todos los problemas ambientales o que la nave podrá zarpar a nuevos destinos dentro o fuera de este planeta.

Todos tendemos a pensar que vemos las cosas como son, que somos objetivos. Pero no es así. Vemos el mundo, no como es, sino como somos nosotros o como se nos ha condicionado para que lo veamos. Cuando abrimos la boca para describir lo que vemos, en realidad nos describimos a nosotros mismos, a nuestras percepciones, a nuestros paradigmas. ${ }^{8}$

La «dependencia» de modelos de desarrollo, el apego a paradigmas que condicionan, unido a factores propios de una especie humana que tiene dificultad para aprender y reaprender de sus errores, así como de reconocer cada individuo en su justa medida, su nivel de responsabilidad en la protección de la diversidad de la vida, impiden o limitan el ejercicio efectivo del derecho a un ambiente sano y ecológicamente equilibrado, entre muchos otros derechos. Hemos creado muchas herramientas que

\footnotetext{
${ }^{8}$ Stephen Covey, Akifrases.com, acceso: 29 de mayo de 2021, https://akifrases.com/frase/200357
} 
podrían ayudar, tales como políticas o legislación, pero estas no son de utilidad si tienen portillos o sin el compromiso permanente en su aplicación.

Se sigue ante los problemas, actuando en la mayoría de las ocasiones en la misma forma que lo se ha hecho durante más de 200 años, creando políticas, o instrumentos de política, ejercicios interesantes e innovadores, pero el daño ambiental continúa. Se evita analizar, a toda costa, la causa de la causa y buscar allá en lo más profundo las raíces de la insostenibilidad ambiental. Los programas educativos o institucionales no rescatan la cultura y la historia para repasar sobre lo actuado y, por lógica, si se sigue haciendo más de lo mismo, se obtendrá siempre el mismo resultado final, aunque en el medio haya aciertos y resultados esperanzadores. En ausencia de una visión ambiental compartida, se seguirá caminando por diferentes rutas $\mathrm{y}$, en este punto, hay que anotar que una visión compartida es más que unir ideas de diferentes personas o sectores, es crear una fuerza común que guía el día a día, desde cada campo de defensa por la vida.

Como en una montaña rusa, se tiene momentos de grandes logros, luego se va en caída. Como país, se ha invertido gran cantidad de dinero en acciones ambientales $\mathrm{y}$, según las decisiones, estos logros son amenazados. Los gobiernos son de turno, y estos deberían atender los intereses sociales; pero ¿Existen intereses sociales ambientales compartidos impregnados en el ADN de cada habitante de este país? ¿Cuáles son estos intereses? ¿Cuál es la visión de desarrollo? ¿Se comparte el logro de un ambiente sano en las aspiraciones para las presentes y futuras generaciones? Este es el fondo al cual se quiere llegar; más que ser disruptivas, se quiere llamar a la reflexión y acción práctica, para que se actúe, transforme e incida constantemente en el cambio desde el hogar, trabajo, grupos, partiendo desde lo individual.

Solo se sabe que si no se toma consciencia de la propia responsabilidad y la responsabilidad de todas las personas, no se podrá resolver ni mejorar. Se cree firmemente que una educación formadora y crítica es un camino para despertar, pero esta debe asegurar la actuación efectiva en procura del bienestar ambiental. Esta educación debe generarse en todas las esferas, públicas, privadas, formales, informales y no formales; además de que proteger el ambiente no debería ser un conflicto entre grupos, sino una meta compartida sobre la cual trabajar y tomar decisiones. No puede haber personas indiferentes ni «cómodas».

La presente pandemia es un recordatorio de la relación seguridad humana y conservación de biodiversidad, es un recordatorio del riesgo en que nos encontramos, aunque todavía hay mucho debate científico, está comprobado que la alteración del equilibrio de los sistemas naturales (...) aumentan notablemente el riesgo de aparición de enfermedades infecciosas transmisibles al ser humano. La solución pasa por frenar la extinción, mantener la integridad de los ecosistemas, reducir nuestra huella ecológica, luchar contra el cambio climático y asumir que nuestra salud depende de la salud del planeta. ${ }^{9}$

Por lo expuesto, esta educación de la que se habla debe ser un proceso permanente, transformador en lo individual y colectivo, dispuesta a cuestionar y a eliminar paradigmas que han demostrado ser ineficientes para proteger la diversidad de la vida. Debe emplear todas las herramientas y creatividad necesaria para posicionar la

\footnotetext{
${ }^{9}$ Isabella Pratesi et al., Pérdida de naturaleza y pandemia. Un planeta sano por la salud de la humanidad (Madrid: WWF España, 2020), 1.
} 
conservación de la naturaleza como una necesidad fundamental de la especie humana, porque la salvaguarda de ecosistemas y de especies es lo único que podrá asegurar, en mayor medida, el alcance de la salud integral de las presentes y futuras generaciones.

\section{Pruebas de la insostenibilidad ambiental}

El más reciente informe (diciembre de 2018) que preparó el país para el Convenio de Diversidad Biológica, al cual se pertenece desde 1994, indica que las principales presiones directas sobre la diversidad biológica, identificadas en el V Informe presentado en 2010, persisten; a saber: pérdida de hábitat, uso insostenible de los ecosistemas, contaminación y sedimentación, y el cambio climático. A estas se agregan, ocho años después, crecimiento urbano, incendios y explotación pesquera insostenible ${ }^{10}$.

En el VI Informe, entregado dos años antes del bicentenario, con base en la metodología establecida, se estimó el efecto de las presiones identificadas en la biodiversidad y tendencias observadas. El análisis de tendencias integra información de diferentes autorías, criterio experto y datos institucionales. De los 38 elementos de la biodiversidad analizados, se concluye que varias especies y ecosistemas tienden a reducirse o perderse (ver Anexo 1). En conclusión, en el bicentenario, con base en este informe de gobierno, no se ha logrado un ambiente sano y ecológicamente equilibrado; por el contrario, se presentan muchas decisiones de orden político, legal y presupuestario, que podrían contribuir a un mayor deterioro.

Uno de los resultados del informe, según se muestra a continuación, es la identificación de zonas del país, con base en criterio experto, que son más afectadas por un conjunto de presiones específicas, las cuales deberían ser prioritarias para procesos de planificación de conservación y uso sostenible.

Sobre el impacto en las especies, de acuerdo con el MINAE ${ }^{11}$, el listado oficial reporta 279 especies en total, de las cuales 155 (56 \%) están declaradas como especies amenazadas, mientras que 124 (44\%) están en peligro de extinción. Esta lista no incluye información de INCOPESCA, instancia responsable de las especies marinas capturadas. Es importante anotar que, de acuerdo con la misma fuente, en la Lista Roja de especies en peligro que elabora la Unión Internacional para Conservación de la Naturaleza (UICN), Costa Rica muestra un progresivo aumento en el número de especies amenazadas desde 1998. Esta tendencia es contrastante con la reversión del proceso de deforestación reportado por la Secretaría del Proyecto REDD + para el $2013^{12}$, lo cual hace pensar, en el caso de especies terrestres, más que en destrucción de hábitat por deforestación, en su fragmentación o degradación ambiental.

\footnotetext{
${ }^{10}$ MINAE-SINAC-CONAGEBIO-FONAFIFO, 2018.

${ }^{11}$ Ibíd.

${ }^{12}$ German Obando Vargas y Mariela Obando Coronado, Costa Rica uso del suelo: Tras el fin de la deforestación, estrategias y acciones para el uso sostenible de la tierra, San José: Climate Chance, 2020, https://www.climate-chance.org/wp-

content/uploads/2020/09/costarica_usodelsuelo_climatechance_espa.pdf
} 


\section{Figura 1}

Grado de presión sobre los elementos de la biodiversidad, por áreas de conservación de Costa Rica según el VI Informe País para el Convenio de Diversidad Biológica

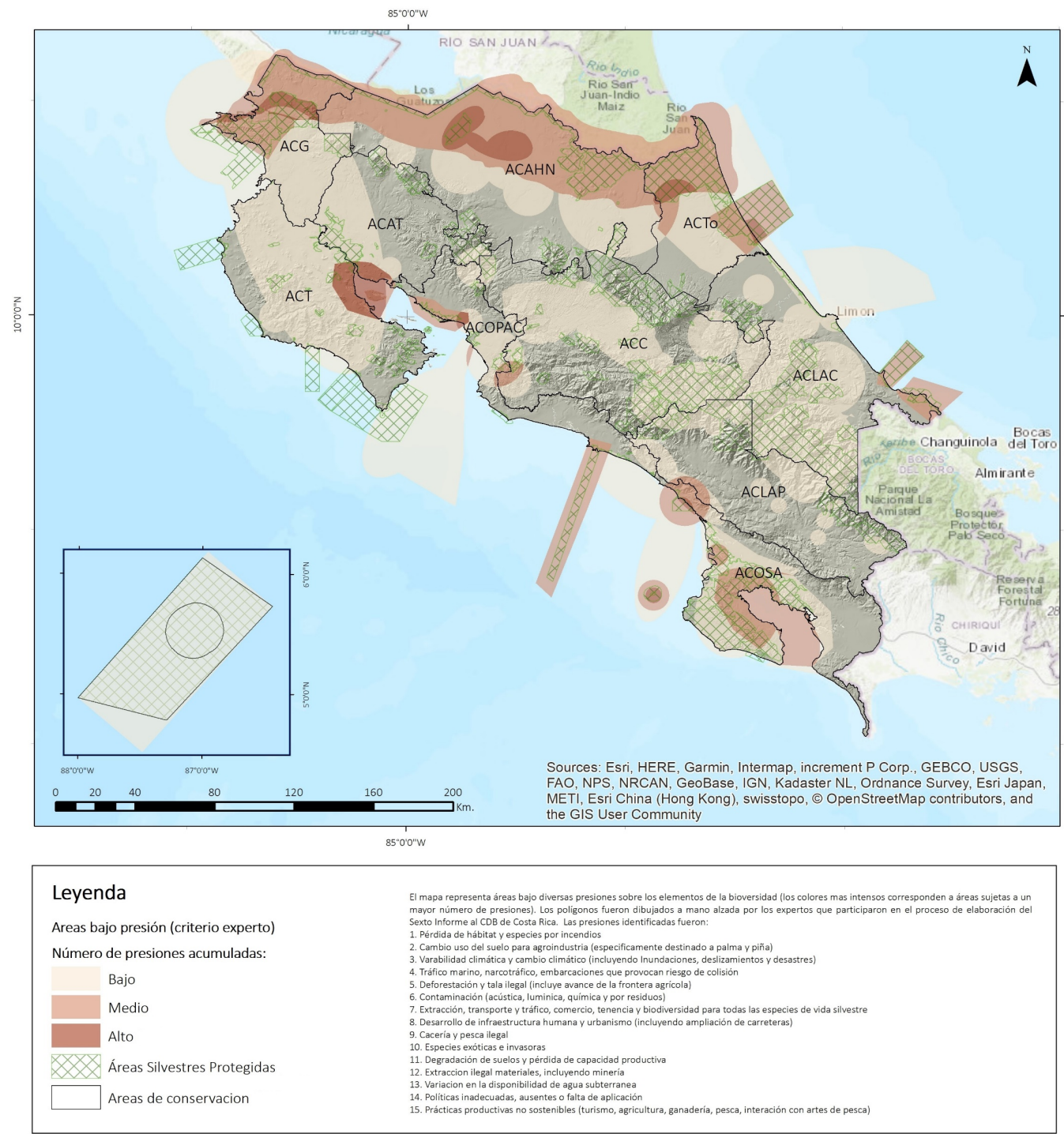

Las áreas del Sistema Nacional de Áreas de Conservación (SINAC) con un área mayor sujeta a presiones diversas, son: Guanacaste (ACG), Huetar Norte (ACHN) y Tortuguero (ACTo). Fuente: MINAE-SINAC-CONAGEBIO-FONAFIFO, 2018. 


\section{Figura 2}

Nivel de presión sobre los elementos de la biodiversidad de Costa Rica por ecorregión, según el VI Informe País para el Convenio de Diversidad Biológica
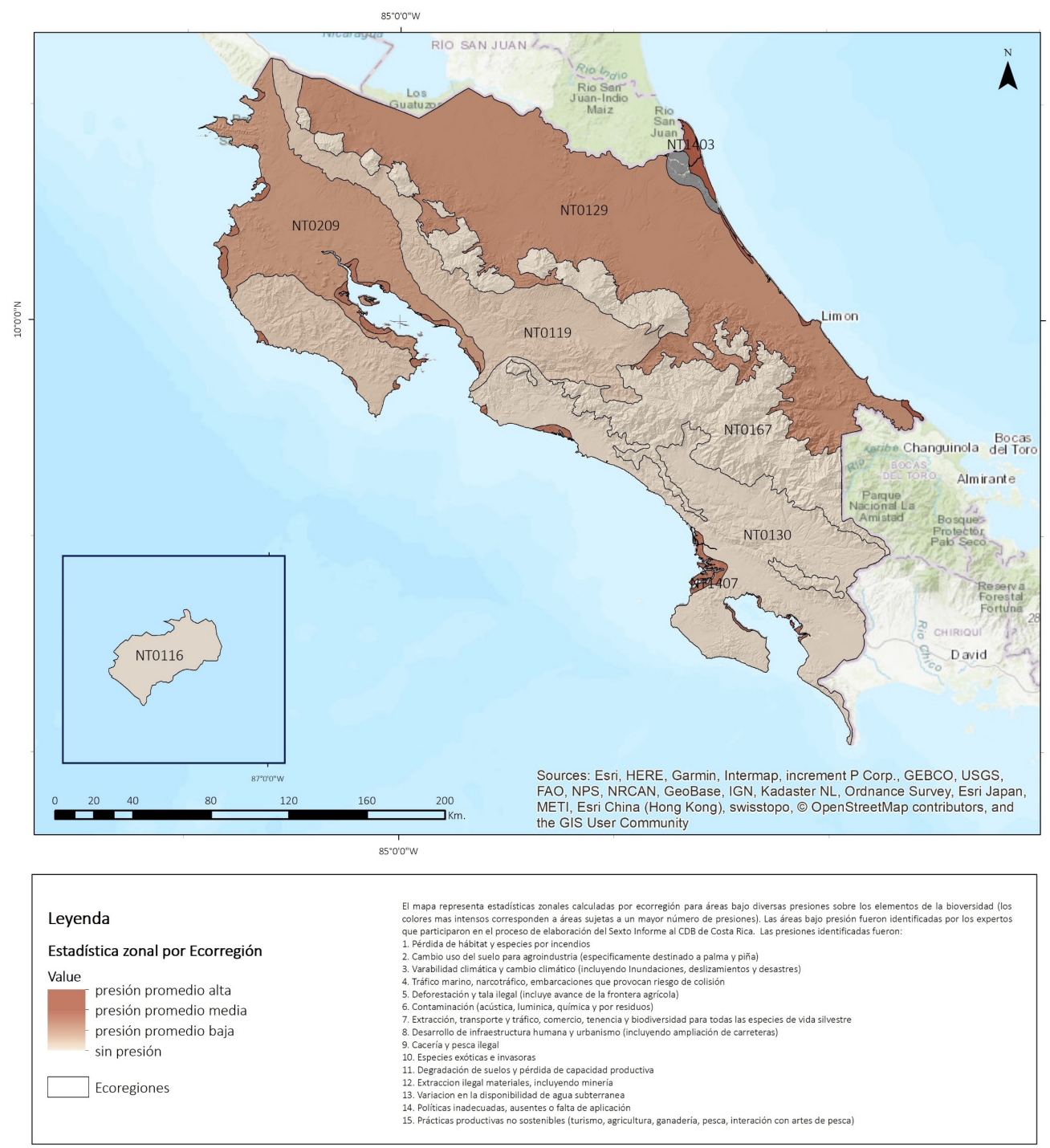

Las ecorregiones con mayores áreas bajo presión promedio son los manglares del Pacífico (NT1407) y del Caribe (NT1403), el Bosque Húmedo Tropical de Istmo del Atlántico (NT0129) y el Bosque Seco Centroamericano (NT0209).

Fuente: MINAE-SINAC-CONAGEBIO-FONAFIFO, 2018.

Más que buenas intenciones y la actuación comprometida de algunas personas $\mathrm{u}$ organizaciones, la falta de alineación entre decisiones puede detener o retroceder los logros alcanzados. Directrices presupuestarias, nueva normativa y decisiones incongruentes, con la meta de un ambiente sano y ecológicamente equilibrado, afectan la gestión de instituciones que tienen responsabilidad en el control y la protección ambiental, la de aquellas que deberían innovar y crear nuevas formas de producción, o bien, de las que implementan mecanismos o instrumentos que coadyuvan a transformar los paisajes. 


\section{Gráfico 1}

Número de especies amenazadas y en peligro de extinción, según VI Informe País para el Convenio de Diversidad Biológica

Amenzada En peligro

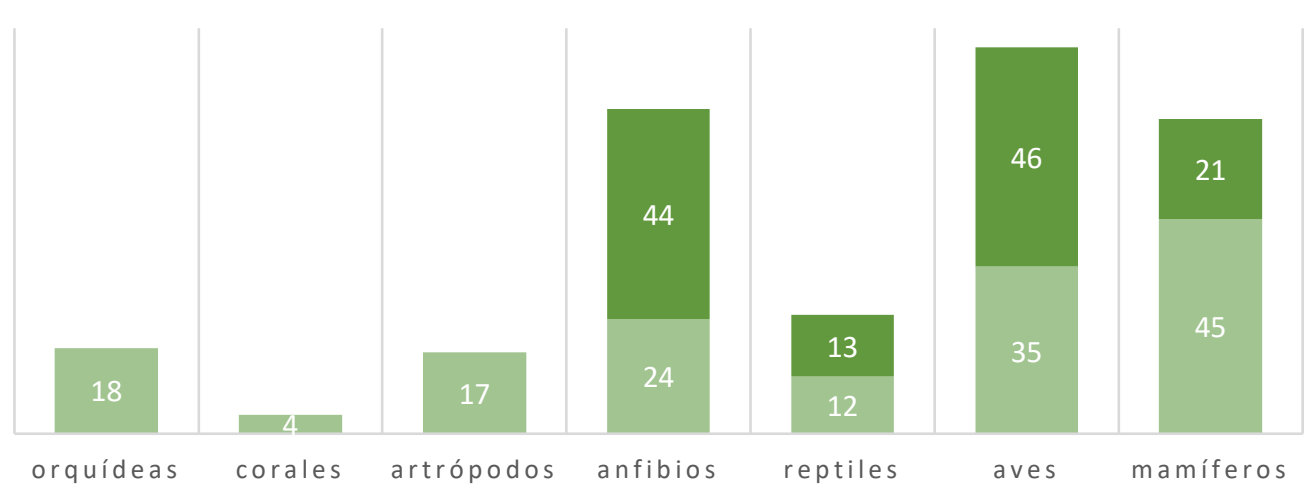

Fuente: MINAE-SINAC-CONAGEBIO-FONAFIFO, 2018.

Nada más cierto que un elemento tóxico -químico, paradigma, intereses- puede destruir el esfuerzo de muchos años. Se tiene amenazas dentro y fuera de Costa Rica y su defensa no puede ser postergada. La creatividad responde si se le invoca y esta permitiría crear una producción que conserve la biodiversidad. Hay que invertir en conocimiento, en innovación, en desarrollo de una cultura ambiental.

Se debe anotar que, aun cuando el Sistema Nacional de Indicadores Ambientales (SINIA) del MINAE (creado por decreto en 2001), se fortalece a partir de 2010, y que se cuenta con el Sistema de Cuentas Ambientales Nacionales del Banco Central (creado en el 2018), el país no dispone de un sistema consolidado de indicadores ambientales que sean correlacionados con indicadores económicos y sociales, según manda la Ley Orgánica del Ambiente 7554 de 1995. A la fecha, se dispone de información, no toda accesible, la cual pocas veces es comparable por metodología o por temporalidad. De hecho, un comparativo histórico, lo que presenta son estimaciones o modelajes.

En esta situación crítica se suma la pandemia, condición que ha sido particularmente reveladora, porque el concepto de salud sigue teniendo una connotación completamente humana. Los protocolos no incluyen la racionalidad en el uso del agua o en la selección de materiales de protección ni el manejo de residuos sólidos. En las medidas tomadas, por las múltiples justificaciones válidas que existan, el refuerzo a la protección del ambiente y el fortalecimiento de las instituciones vinculadas no ha sido considerado en las medidas de emergencia, aun cuando dicha acción es requerida para prevenir futuras pandemias. Parece ser que Costa Rica no se caracteriza por ser un país previsor con horizonte de largo plazo. Por lo tanto, la idea de que el país tiene como prioridad el tema ambiental, no es tan real y la pandemia lo expone claramente. A lo largo de este 2021 se ha debido realizar mucha presión para que las instancias competentes autoricen, aunque sea de última hora, recursos financieros para la conservación. 


\section{El tema ambiental, un sube y baja}

La historia de la situación ambiental de Costa Rica es una obra inconclusa. Mezcla elementos propios cargados de grandes emociones, en ocasiones más precisas, en otras muy complejas, en muchos momentos muy oscuras, y en otras con gran luz que abre la esperanza de un mejor mañana. Sabores y sinsabores, errores y aciertos; conocimiento y desconocimiento; egoísmo y amor; respeto y destrucción; ignorancia y locura; instinto y pasión. Sigue presente la codicia, la avaricia, la inconciencia.

En 2018, el VI Informe País cuestionaba los resultados alcanzados por la sociedad, más que por un gobierno, y en 2019 Costa Rica se enorgullecía por alcanzar el premio Campeones de la Tierra por el liderazgo político. El equilibrio ecológico y la salud ambiental no puede depender de acciones puntuales, debe ser una realidad construida por cada habitante, día a día, para ser campeones en cada uno de ellos, para sostener el título a lo largo del tiempo.

Podría resumirse que el ambiente del bicentenario, más que celebrar dos siglos de independencia, muestra, en términos generales, una Costa Rica que desconoce sus orígenes, que insiste en reproducir acciones de un pasado ambientalmente nefasto, $\mathrm{y}$ que tiene dificultad para apropiarse y aferrarse, como una sociedad diversa y democrática, de muchos logros que también le caracterizan. Se es un país que, gracias a decisiones de sus gobiernos, aprovecha oportunidades, pero no siempre suman a la conservación de la biodiversidad ni a la sostenibilidad ambiental en el desarrollo.

Se sigue transitando entre actos meritorios y errores, repitiéndolos, sin precisar el final de la obra, sin un involucramiento, como sociedad, en un $100 \%$ en el logro de un cierre de telón que favorezca a cada habitante y visitante; la única forma real que puede tener este final es legitimando y asegurando el derecho a un ambiente sano y ecológicamente equilibrado, de cada persona, pero también de cada ser viviente que habita en este país.

A estas alturas no se debería tener dudas sobre lo que es bueno y lo que no lo es para el ambiente, lo que es bueno y no para la salud y el desarrollo.

\section{Abandono de un modelo de desarrollo sostenible}

Los pueblos originarios de Costa Rica vivían en armonía con la naturaleza, en un terreno prácticamente cubierto por bosques. Describe Luis Fournier ${ }^{13}$ que habían logrado desarrollar una forma sostenible de convivencia con su ambiente natural, evitando su deterioro, aun cuando lograban obtener de él todo lo necesario para satisfacer sus necesidades. Estos habitantes heredaron elementos desconocidos o no reconocidos y, en términos prácticos, fueron los primeros conservacionistas del país.

Viajeros como el inglés John Baily, quien estuvo en Costa Rica, publica en $1850 \mathrm{su}$ travesía y describe el entorno como «toda la bella ferocidad de la naturaleza»" 14 . Thomas Francis Meagher ${ }^{15}$, en 1858, llamaba «las excelsitudes de la naturaleza» al ambiente en que se habita hace 200 años y así es posible que ese territorio no quepa ahora ni siquiera en la imaginación del país.

\footnotetext{
${ }^{13}$ Luis Fournier Origgi, Desarrollo y perspectivas del movimiento conservacionista costarricense (San José: Editorial Universidad de Costa Rica, 1991).

${ }^{14}$ Miguel Ángel Quesada Pacheco, Entre silladas y rejoyas. Viajeros por Costa Rica de 1850 a 1950

(Cartago: Editorial Tecnológica de Costa Rica, 2001), 38.

${ }^{15}$ Idíd., 70.
} 
A partir del siglo XVI, y hasta la independencia que se celebra en este 2021, se implantó un nuevo modelo de desarrollo, producto de una realidad cultural y social muy diferente a la actual. Un modelo agropecuario que transformó el paisaje, a uno deforestado o deteriorado. Los ecosistemas naturales cedieron al paso de los sistemas productivos propios de otros países.

La introducción a Costa Rica del ganado caballar y vacuno, en 1561, marcó el inicio de un cambio en el uso de la tierra, que ha tenido repercusión hasta la época contemporánea (...) el español trajo a Costa Rica muchas de sus plantas cultivadas y con ellas también vinieron plantas silvestres europeas; junto a un "choque de culturas". 16

Contrario a una de las famosas frases del libro El Principito ( $« \mathrm{Si}$ me domesticas tendremos necesidad el uno del otro. Tú serás para mí único en el mundo. Yo seré para ti único en el mundo» ${ }^{17}$ ), el modelo implantado no reconoce, por parte de una gran mayoría de visitantes, la unicidad de los ecosistemas naturales ni la necesidad o dependencia de ellos, se veía como un espacio para usar.

Excepcionalmente, algunos tomadores de decisión, conscientes del daño que las actividades de transformación causaban, empezaron a tomar decisiones para evitar más daño al ambiente. Menciona Fournier ${ }^{18}$ al gobernador Juan Fernández, que, de acuerdo con su libro, en 1775 fue uno de los primeros en mostrar preocupación por lo ambiental. «La forma de pensar del gobernador Fernández de Bobabilla no representaba en realidad una tendencia significativa en la corriente de pensamiento de los pobladores (...), era más bien una excepción, un pensamiento de avanzada» ${ }^{19}$.

\section{El primer centenario (1821-1921)}

Antes de llegar al bicentenario, se suscitaron más transformaciones. Un cultivo de café que cambió más el paisaje, en zonas en las que habían sido sembrados cultivos ajenos a la realidad ecológica. Era una «(...) planta que en los primeros 40 años del siglo XIX comenzó a cambiar la fisonomía del Valle Central, donde antes predominaban los cultivos de maíz, frijoles, caña de azúcar, tabaco y trigo ${ }^{20}$.

De acuerdo con Fournier ${ }^{21}$, «las obras de los últimos gobiernos del siglo XIX le habían dado al país un gran impulso económico, fundamentado primero en el café y posteriormente en la rápida expansión del cultivo del banano a raíz de la construcción del ferrocarril»». Para 1900, la población superaba los 300000 habitantes y había un $13.5 \%$ de deforestación; no es hasta en 1906 que se elabora un primer proyecto de ley forestal, el cual fue archivado.

En este período, algunos gobernantes del país se mostraban preocupados por problemas ambientales y promulgaron numerosos decretos y leyes. «Se observa aquí uno de los grandes problemas que ha tenido el país a lo largo de su historia, en relación con las leyes y reglamentos de protección ambiental, son las buenas intenciones en la letra, pero poco efecto en la realidad ${ }^{22}$. A modo de ejemplo sobre esta afirmación, la Ley de Aguas $\mathrm{N}^{\circ} 11$ del 26 de mayo de 1884, estipulaba la

\footnotetext{
${ }^{16}$ Fournier Origgi, Desarrollo y perspectivas..., 14-15.

${ }^{17}$ De Saint-Exupéry, El Principito, 74.

${ }^{18}$ Fournier Origgi, Desarrollo y perspectiva ..., 17-18

19 Ibíd., 18.

${ }^{20}$ Ibíd., 19.

${ }^{21}$ Ibíd., 35.

${ }^{22}$ Ibíd., 23-24.
} 
obligación de mantener una franja de 50 metros en cada ribera de los ríos, esta área de protección sigue siendo prácticamente ausente hoy, especialmente en zonas urbanas.

Desde esta época, se mostraba el poco cuidado por el tratamiento de aguas negras y servidas, los ríos recolectaban y transportaban los errores de un desarrollo ambientalmente no sostenible. Por otra parte, este período trae nuevas influencias al país, en materia de investigación, tendencias conservacionistas de otros países, extracción de recursos genéticos por parte de personas viajeras y científicas, la enseñanza de las ciencias naturales, el sistema educativo público, la creación del Museo Nacional y mucho más ${ }^{23}$.

Esta gran actividad en la promulgación de leyes y reglamentos de protección ambiental, que tuvo lugar en los primeros 25 años» del siglo XX, «se debió en mucho a la influencia de varios costarricenses principalmente agrónomos y médicos, que habían tenido la oportunidad de realizar estudios en el exterior. $^{24}$

«Este grupo de profesores de la Escuela Nacional de Agricultura, comienza a darle forma al movimiento conservacionista costarricense (...), mostraron tanto en las aulas como en lo que escribieron, una gran preocupación por el uso racional de los recursos forestales del país» ${ }^{25}$.

\section{El segundo centenario (1921-2021)}

Posterior a 1921, fue fortalecida la plataforma educativa, se continuó con la creación de normativa ambiental, con la preocupación conservacionista, con una cultura de investigación y publicaciones, un país más integrado a realidades internacionales y a organizaciones que influyen en la toma de decisiones ambientales. En sus inicios, fue una época en la que «pocos costarricenses se preocupaban entonces por reforestar y también pocos los extranjeros que lo hacían» ${ }^{26}$. Según Fournier ${ }^{27}$

entre 1948 y 1957 el país vivió una época de gran interés por el uso racional del ambiente y si todas las buenas intenciones se hubieran hecho realidad la situación actual podría haber sido otra. (...) esta época coincidió con una alta tasa de crecimiento demográfico (...) se produjo una gran presión por el desarrollo de nuevas tierras para satisfacer las crecientes demandas de la población, y muchas tierras de vocación forestal fueron dedicadas a otras actividades, para las que no están preparadas(...) Un 65 a un 70 por ciento está cubierto de bosques (...) hay serios problemas para protegerlos. ${ }^{28}$

Es un período particularmente intenso, con marco legal y funciones vinculantes a instituciones u organismos, los cuales no siempre eran ejecutados, como ejemplo se tiene la Ley $\mathrm{N}^{\circ} 495$ del 19 de abril de 1949, la cual creaba un organismo que debería gestar un inventario forestal nacional, municipal y particular; sin embargo, este ente nunca llegó a ser implementado.

Ante la ausencia de ejecución de funciones o implementación de mecanismos creados por el marco jurídico, se debe mencionar que al país le tomó 63 años contar

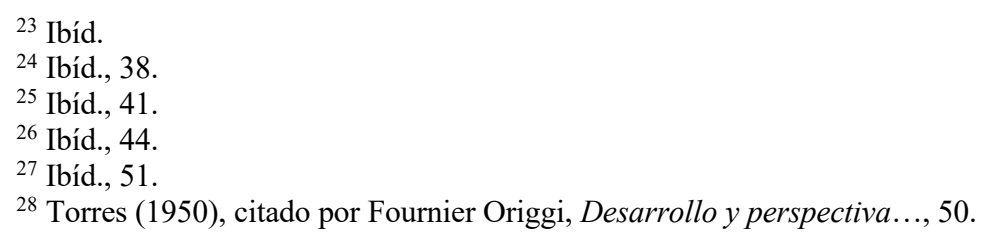


con una ley forestal (en 1969), luego de la intención expresada en 1906. Esta realidad aconteció 65 años posteriores al mandato de 1949, de realizar un primer inventario forestal, el cual fue elaborado en 2013, y fue hasta en el presente siglo que se dispone de un Sistema de Información de Recursos Forestales ${ }^{29}$. A modo de reflexión ¿Cuánto recurso forestal habrá quedado fuera del inventario realizado en 2013 ?

El aspecto más placentero de la naturaleza, decrece al cubrir el hombre mayores áreas con sus carreteras y construcciones, destruir bosquesprósperos para hacer campos cultivados y potreros para su ganado de engorde, contribuir a la expansión de los desiertos por la explotación excesiva de las tierras áridas y envenenar los mares con sus desechos. ${ }^{30}$

Posterior a 1960, en coincidencia directa con el interés del tema ambiental a nivel mundial, se logró mayor normativa, creación de instituciones, realización de eventos diversos, actualización y profesionalización. Un hito de esta época es la creación del Sistema de Parques Nacionales, la Dirección Forestal y la Dirección de Vida Silvestre, entre muchas otras instituciones.

Sumando a las contradicciones, merece anotar que, entre 1950 y 1970, se produjo un desarrollo industrial, fundamentado principalmente en la sustitución de importaciones y la tecnificación con el uso de productos químicos, sumando a la preocupación conservacionista sobre la deforestación, la erosión y la contaminación, según lo manifiesta Fournier ${ }^{31}$ en su obra.

Entre 1970 y 1990, se transita por nuevos problemas ambientales y, también, por procesos de organización de personas y grupos sociales que buscaban la defensa ambiental, solo para citar el caso de Olof Wessberg, quien junto con su esposa Karen Mogensen, ayudó a crear la Reserva Natural Absoluta de Cabo Blanco. En 1974 Wessberg fue asesinado en Corcovado por su guía, temeroso de que este sitio fuera convertido en un área protegida. Pese al asesinato, gran parte de esta zona fue declarada como parque nacional en $1975^{32}$. «El sueco dio su vida por proteger nuestros bosques. Ahora, es responsabilidad de Costa Rica lograr su sueño para que haya un parque nacional en Corcovado» ${ }^{33}$.

En la década de 1990, en términos de generación de ingresos, la actividad turística empieza a suplantar actividades agrícolas como el café y el banano, así se dan fuertes presiones para que estas últimas sean más amigables con el ambiente. «En la actualidad, una cuarta parte de los ingresos de exportación de Costa Rica provienen del turismo y el ecoturismo es la forma más destacada de turismo en el país» ${ }^{34}$. «El ecoturismo ha sido una estrategia efectiva para restaurar los bosques, y la protección de los bosques vulnerables de alto valor por cuanto ha estado acompañado de un mecanismo de conservación explícito» ${ }^{35}$.

\footnotetext{
${ }^{29}$ Se puede visitar el sitio MINAE/SIREFOR (Sistema integrado de manejo de la información forestal del país), en: https://www.sirefor.go.cr/

${ }^{30}$ Alexander Skutch, La finca de un naturalista, citado por Fournier Origgi, Desarrollo y

perspectiva... (1985), 53-54.

${ }^{31}$ Fournier Origgi, Desarrollo y perspectiva...

${ }^{32}$ Agneta Tjader, «Olof Wessberg y Karen Moegensen: gestores de la creación de la Reserva Natural Absoluta Cabo Blanco», Revista Biocenosis 28, n. ${ }^{\circ}$ 1-2 (2014): 38-43.

${ }^{33}$ Tjader, «Olof Wessberg y..., 42-43.

34 Obando Vargas y Obando Coronado, Costa Rica uso del suelo...

${ }^{35}$ Brandt y Buckley (2018), citado por Obando y Obando (2020), 11.
} 
La presión internacional y nacional es tan fuerte en este período, que en el país se adoptan o desarrollan estándares para una agricultura sostenible, tanto social como ambientalmente y se implementan algunas innovaciones. Los grupos conservacionistas ejercen fuertes presiones contra la contaminación, la deforestación y sobre cualquier actividad que impacte el ambiente y ponga en riesgo el bienestar de las personas. Entre 1994 y 1995 mueren, por causas poco claras, cuatro miembros de la Asociación Ecologista Costarricense (AECO) ${ }^{36}$.

En 1995, la responsabilidad ambiental de cada habitante del país, se afirma en los principios establecidos en el artículo 2 de la Ley Orgánica del Ambiente, que claramente define al ambiente, como un sistema, constituido por los diferentes elementos naturales que lo integran y sus interacciones e interrelaciones con el ser humano. Esta Ley, publicada 26 años antes del bicentenario, establece formas de actuación para todos los integrantes del Estado, incluyendo a los individuos, por cuanto se reconoce el valor del ambiente.

«El ambiente es patrimonio común de todos los habitantes de la Nación (...) El Estado y los particulares, deben participar en su conservación y utilización sostenibles, que son de utilidad pública e interés social». Según el artículo 50 de la Constitución Política, todas las personas tienen derecho a disfrutar de un ambiente sano y ecológicamente sostenible para desarrollarse, así como el deber de conservarlo.

«El Estado velará por la utilización racional de los elementos ambientales, con el fin de proteger y mejorar la calidad de vida de los habitantes del territorio nacional. Asimismo, está obligado a propiciar un desarrollo económico y ambientalmente sostenible, entendido como el desarrollo que satisface las necesidades humanas básicas, sin comprometer las opciones de las generaciones futuras».

«Quien contamine el ambiente o le ocasione daño será responsable, conforme lo establezcan las leyes de la República y los convenios internacionales vigentes».

«El daño al ambiente constituye un delito de carácter social, pues afecta las bases de la existencia de la sociedad; económico, porque atenta contra las materias y los recursos indispensables para las actividades productivas; cultural, en tanto pone en peligro la forma de vida de las comunidades; y ético, porque atenta contra la existencia misma de las generaciones presentes y futuras» 37

Sin embargo, igual que en épocas anteriores, la publicación de la Ley 7554 dista de su implementación. Por ejemplo, esta Ley no está reglamentada en un $100 \%$, no dispone de las condiciones presupuestarias para su efectiva operacionalización y normativa que ha sido creada a su amparo no es implementada por diversas razones, aun cuando esta ley debería garantizar un desarrollo ambientalmente sostenible.

A modo de ejemplo, en cuanto a incumplimiento de objetivos y expectativas de instrumentos legales publicados, el caso de la llamada Trocha Fronteriza (refiérase a la construcción de la carretera 1856 en la frontera norte), generó una serie de impactos ambientales a inicios del presente siglo, además de reconocidos actos de

\footnotetext{
${ }^{36}$ Informe Peticionario, OJ-004-97, del 23 de enero de 1997, disponible en SINALEVI.

${ }^{37}$ Ley Orgánica del Ambiente, 1995, Art. 2.
} 
corrupción y malversación de fondos. De acuerdo con informes y análisis realizados, los cuales no coinciden en números algunos de ellos, el área fue deforestada, se invadieron y afectaron fuentes de agua, y estas fueron contaminadas. Se mostró daño de ecosistemas como humedales, supuestamente amparados por diversa normativa ${ }^{38}$.

Los instrumentos de política pueden ser útiles, en manos honradas y comprometidas con el bienestar ambiental y social, en manos inescrupulosas y materialistas, son desviados a favor de intereses particulares, causando grave daño al presente y futuro del país, y de las zonas específicas.

En relación con los principios antes citados de la Ley 7554, según $\mathrm{FAO}^{39}$

entre 1986 y 2015, el Estado costarricense realizó una inversión total de US\$ 318 millones en la recuperación de áreas boscosas, establecimiento de plantaciones forestales, sistemas agroforestales y conservación y uso sostenible del bosque, en tierras privadas. Mediante instrumentos legales promulgados en dos leyes forestales (en 1986 y 1996), la Ley de Vida Silvestre (1998) y la Ley Orgánica del Ambiente (1995), se erigieron fondos públicos importantes.

Resultado de esta inversión, entre 1997 y 2015, Costa Rica revirtió el proceso de deforestación, alcanzando más de un $54 \%$ de cobertura forestal y, de acuerdo con Obando y Obando, se logró reducir 166 millones de toneladas de emisiones de $\mathrm{CO}_{2} \mathrm{e}$ $\left(\mathrm{MtCO}_{2} \mathrm{e}\right)$ a la atmósfera. De acuerdo con REDD+, citado por este mismo autor ${ }^{40}$, la deforestación en Costa Rica es actualmente de 17312 hectáreas anuales, siendo los bosques en propiedad privada los más vulnerables a la deforestación, junto con los bosques secundarios $(77 \%)^{41}$.

«El principal factor que impulsa la deforestación en los terrenos privados es la conversión de los bosques para el uso agrícola y ganadero. Esta dinámica va en doble sentido, siendo las pasturas las que más aportan a la regeneración del bosque natural ${ }^{42}$. Por otra parte, según Gonzalo ${ }^{43}$, «155 023 hectáreas fueron afectadas por la degradación forestal en el periodo 2005-2015, lo que representa un 7,0\% del área de bosques primarios (...), no obstante, las emisiones de la degradación forestal son significativas y se estiman en más de $2 \mathrm{Mt}$ anuales de $\mathrm{CO}_{2} »$.

Este aspecto de la degradación es de alerta, porque resulta un problema visualizar datos gruesos, como porcentaje de cobertura forestal, que no expresan la realidad sobre el deterioro de dicha cobertura. Por otra parte, la fragmentación mencionada en el VI Informe país afecta la biodiversidad. Fischlin indica que

los remanentes de ecosistemas de menor tamaño son severamente afectados por la fragmentación y solo pueden sostener pequeñas poblaciones las cuales tienden a volverse más vulnerables a la extinción en la medida en que el tamaño de los relictos disminuye. (...) Se espera que las personas que viven

\footnotetext{
${ }^{38}$ Mauricio Álvarez, «Daños ambientales generados por la construcción de la carretera 1856. Agua en Centroamérica: Oportunidades para la solución de conflictos», Costa Rica, 2012, disponible en: http://tragua.com/wp-content/uploads/2012/12/impactos-ambientales-de-la-trochafronterizaMauricio-Alvarez.pdf

${ }^{39}$ FAO, citado por Obando y Obando, 2020.

${ }^{40}$ Obando Vargas y Obando Coronado, Costa Rica uso del suelo...

${ }^{41}$ Ibíd.

${ }^{42}$ Ibíd.

${ }^{43}$ Gonzalo (2017), citado por Obando y Obando, 2020.
} 
en las zonas rurales pobres sufrirán los mayores impactos debido a su fuerte dependencia de los ecosistemas y sus servicios ${ }^{44}$.

En oposición a la recuperación de cobertura forestal, $\mathrm{FAO}^{45}$ indica que

Costa Rica sobresale por el alto uso de plaguicidas (...), en 2016 se utilizaron 12,8 millones de toneladas de estas sustancias. Si se compara con el uso de los países centroamericanos, se tiene que este valor únicamente fue superado por Guatemala, que en ese mismo año consumió 20,5 millones toneladas.

Según Chacón ${ }^{46}$,

un sector en el cual se manifiesta de forma marcada y reiterada las implicaciones del alto uso de plaguicidas en el país es el hídrico. Estudios efectuados por centros de investigación y laboratorios de las universidades públicas, han reportado la presencia de residuos provenientes de agroquímicos en distintos cuerpos de agua. Uno de los casos más emblemáticos es el acueducto El Milano en Siquirres de Limón (...) Un caso más reciente se presentó en la zona norte del país, específicamente en las comunidades de Pital, Aguas Zarcas y Río Cuarto.

Por su parte, el CICA-UCR ${ }^{47}$, entre 2015 y 2017, evaluó más de 120 ingredientes activos en aguas subterráneas, se constató que el Bromacil presentó un valor mayor al límite que establece la regulación nacional. «En el caso de aguas superficiales el Bromacil, la Ametrina y el Diurón (...) fueron los plaguicidas más frecuentemente detectados y cuantificados en muestras de ríos y quebradas». Para beneficio del ambiente y la salud, el Bromacil fue prohibido por el gobierno para su importación a partir del 24 de mayo del 2017 y para su uso a partir de noviembre del mismo año. Este centro de la UCR, en el 2014, también encontró contaminación por pesticidas en el humedal Térraba-Sierpe, a pesar de ser este un sitio RAMSAR $^{48}$ de importancia internacional.

Una vez más, la historia muestra que, a pesar de la creación de instrumentos, el cambio efectivo y sostenido no sucede. Aun cuando la Ley Orgánica del Ambiente en su capítulo XVI indica, desde hace 26 años, la responsabilidad del Estado de promover la agricultura ecológica, y que en 2007 se dotó de una ley específica, la 8591, para este fin:

en los últimos 20 años la extensión cultivada de productos orgánicos se ha mantenido similar, aunque sigue representando un porcentaje bajo $(1,9 \%)$ del área total agrícola nacional, a junio del 2020 se contabilizan 98 operadores orgánicos certificados, los cuales pueden ser personas que se dedican a la producción con finca individual o en grupo, procesamiento,

\footnotetext{
${ }^{44}$ Fischlin (2007), citado por MINAE-SINAC-CONAGEBIO-FONAFIFO, 2018.

${ }^{45}$ Karen Chacón Araya, «Investigación de base. Agricultura y sostenibilidad ambiental en Costa Rica», en Informe Estado de la Nación en Desarrollo Humano Sostenible 2019, ed. por Estado de la Nación (San José: Programa Estado de la Nación, 2019).

${ }^{46}$ Chacón Araya, «Investigación de base...

${ }^{47}$ Universidad de Costa Rica, «La Universidad de Costa Rica respondió a las consultas de los diputados sobre los plaguicidas», Noticias UCR, acceso: 20 de mayo de 2021, https://www.ucr.ac.cr/noticias/2018/07/20/la-universidad-de-costa-rica-respondio-a-las-consultas-delos-diputados-sobre-los-plaguicidas.html

${ }^{48}$ La Convención Internacional Intergubernamental, denominada RAMSAR, protege los ecosistemas de humedales del mundo. Fue firmado en 1971. Consulta:

https://www.ramsar.org/sites/default/files/fs_6_ramsar_convention_sp_0.pdf
} 
comercialización o exportación de productos orgánicos. De estos, 58 corresponden a productores y productoras orgánicos (59,2\% de operadores certificados), que en conjunto reúnen 10.064,41 hectáreas de cultivos orgánicos en el país. ${ }^{49}$

Muy cerca del bicentenario, el MINAE prepara un oficio sobre la situación de la explotación ilegal de oro en Crucitas y las afectaciones ambientales asociadas ${ }^{50}$. El tema Crucitas inicia en 2001, el proyecto contó con una declaratoria de interés público y de conveniencia nacional, cuyo decreto fue anulado en 2011. Abandonado el sitio, inicia la explotación ilegal de oro en 2017 y, de acuerdo con los estudios realizados, por la actividad se ha generado, deforestación, contaminación de suelos y de aguas, afectación de ríos ${ }^{51}$.

Este es un ejemplo más de la desatención ciudadana, de las organizaciones, de la institucionalidad pública y de las contradicciones entre sectores; ya que, para la extracción ilegal, miembros de la zona han brindado desde transporte hasta hospedaje a las personas que han causado el daño ambiental.

\section{Más que buenas acciones, cambiar paradigmas}

Tenemos que pasar del viejo paradigma caracterizado por la fragmentación, el dualismo, la desconexión y la división, al nuevo paradigma de la integridad, la conectividad y la relacionalidad. (...) Según el viejo paradigma la economía está basada en el principio de linealidad: toma, usa y desperdicia. En el nuevo paradigma la economía será cíclica como la naturaleza (...): sin desperdiciar, sin contaminar y sin agotar.

- Satish $\mathrm{Kumar}^{52}$

En razón de sus acciones, muchas de ellas meritorias, Costa Rica es un referente a nivel mundial. Cuenta con más de un $27 \%$ del territorio en áreas silvestres protegidas y un porcentaje similar en corredores biológicos ${ }^{53}$; además ha suscrito más de 50 tratados ambientales, entre ellos, la Convención Marco de las Naciones Unidas sobre el Cambio Climático (CMNUCC), ratificada con la Ley No. 7414 de 1994, el Acuerdo de París aprobado con la Ley No. 9045 del año 2016, el Convenio sobre la Diversidad Biológica Ley No. 7416 de 1994 y la Convención de Lucha contra la Desertificación, la Degradación de la Tierra y la Sequía, Ley No. 7699 de 1997.

Además, conceptos como ecoturismo o turismo sostenible están posicionados, han sido implementadas mejoras ambientales en diferentes actividades productivas y se encuentran en marcha programas y proyectos con enfoque transformacional. Las buenas prácticas ambientales se reconocen, entre otros factores, mediante incentivos financieros como el programa de pago por servicios ambientales; programas como el Certificado de Sostenibilidad Turística del Instituto Costarricense de Turismo; el Programa C-Neutral del Ministerio de Ambiente y Energía, el Sistema de Reconocimientos Ambientales del MINAE.

\footnotetext{
${ }^{49}$ Servicio Fitosanitario del Estado, MAG-Costa Rica, «Registro de Agricultura Orgánica (ARAO), acceso: 16 de mayo de 2021, https://www.sfe.go.cr/SitePages/ARAO/InicioARAO.aspx

${ }^{50}$ Oficio DM-0154-2020, MINAE, 2020.

${ }^{51}$ MINAE, 2020.

${ }^{52}$ Satish Kumar, «El nuevo paradigma frente al viejo paradigma», mundonuevo.cl, https://www.mundonuevo.cl/el-nuevo-paradigma-frente-al-viejo-paradigma/

${ }^{53}$ MINAE-SINAC-CONAGEBIO-FONAFIFO, 2018.
} 
Las buenas intenciones son amplias y meritorias, pero no aseguran, como se ha visto con los ejemplos anteriores, la protección ambiental y la conservación de la biodiversidad. El proceso parece avanzar lento y, esta lentitud, pone cada vez más en riesgo el futuro de la ciudadanía. Históricamente existe una incongruencia latente en el accionar político, colectivo e individual, se avanza en unos temas a medias, se retrocede en otros, o bien, en el peor de los casos, no se aborda el tema generalmente por razones económicas. La comprensión de que la salud humana depende de la salud del planeta, se denota en la gestión realizada mundialmente ante la pandemia que inició en 2020. El COVID-19 no es la primera pandemia de origen zoonótico, además hay nuevos virus en curso. Se está enfocado en resolver sobre lo urgente y no en prevenir o controlar el desarrollo de nuevas pandemias, lo cual requiere asegurar la protección de la biodiversidad.

Resulta asombroso que transcurran tantos años para el desarrollo de normativa ambiental y muchos más para iniciar o concretar sus resultados, si es que estos llegan en el mejor de los casos. El problema de fondo del derecho ambiental es su aplicación, existe resistencia o condiciones que limitan su efectiva implementación.

Considerando la jerarquía del ordenamiento jurídico descrita en la Ley General de la Administración Pública $\mathrm{N}^{\circ}$ 6227, transcurrieron 45 años para que en la Constitución Política de la República de 1949 se incorporara el derecho a un ambiente sano y ecológicamente equilibrado, además de 71 años para que incluyera el derecho de acceso al agua. En referencia a 1821, se tardó casi el bicentenario para incorporar ambos derechos.

El artículo 50 indica:

El Estado procurará el mayor bienestar a todos los habitantes del país, organizando y estimulando la producción y el más adecuado reparto de la riqueza.

Toda persona tiene derecho a un ambiente sano y ecológicamente equilibrado. Por ello, está legitimada para denunciar los actos que infrinjan ese derecho y para reclamar la reparación del daño causado.

El Estado garantizará, defenderá y preservará ese derecho.

La ley determinará las responsabilidades y las sanciones correspondientes.

Toda persona tiene el derecho humano, básico e irrenunciable de acceso al agua potable, como bien esencial para la vida. El agua es un bien de la nación, indispensable para proteger tal derecho humano. Su uso, protección, sostenibilidad, conservación y explotación se regirá por lo que establezca la ley que se creará para estos efectos y tendrá prioridad el abastecimiento de agua potable para consumo de las personas y las poblaciones. ${ }^{54}$

Diversos estudios indican que la especie humana, en términos generales, no aprende fácilmente de los errores, pero sí acumula los aciertos. Más allá de culpar a grupos o personas particulares, es de interés mostrar que la protección del ambiente no es una práctica habitual en Costa Rica, no es un hábito del $100 \%$ ni de al menos del 50 $\%$ de los individuos y de la colectividad, como podría suponerse es el de lavarse los dientes o el de bañarse o bien de comer. Y contrario a otras épocas, parece que se ha perdido beligerancia para defender la salud integral $y$, en consecuencia, al ambiente

\footnotetext{
${ }^{54}$ Constitución Política de la República de Costa Rica (1949), Art. 50.
} 
del cual ella depende. Son aislados los eventos de presión por productos y servicios respetuosos de la naturaleza, pocos los que los adquieren y menos aún son los actos manifiestos para exigir el respeto a la naturaleza. Son otros los temas que parecen preocupar al colectivo o a parte de este: canasta básica, impuestos, empleo, aumentos salariales, pluses salariales, derechos humanos. Estos grupos no comprenden que la satisfacción de las necesidades fundamentales depende de la conservación de la biodiversidad.

Pese a la existencia de algunas empresas meritorias, la globalización, aceptada en mayor o menor medida, ha llenado de negocios que venden barato, aunque el costo ambiental y social de la producción y eliminación de sus productos sea cara, si es que estos se eliminan. Se socializan los impactos negativos, no así las ganancias. La visión extractiva de unos y consumista de muchos ha causado y seguirá causando la destrucción de la estabilidad ambiental, así como pisoteando el derecho a la vida de muchas otras especies.

En mayor o menor medida, cada persona es responsable del resultado, unos por su codicia, otros por su avaricia, otros por su complacencia, otros por su ignorancia, otros por dependencia, otros por inconciencia. No es suficiente con dirigir la vista hacia la producción insostenible, hacia la política incongruente, se requiere observar y reconocer el actuar diario de cada persona.

«Los seres humanos somos el único elemento de la naturaleza que genera basura ${ }^{55}$; solo por poner un ejemplo, cada latinoamericano produce un kilo de basura al día ${ }^{56}$ y la región en su conjunto, unas 541000 toneladas diarias. Esto representa alrededor de un $10 \%$ de la basura mundial.

De igual gravedad que los residuos es el problema de la explotación de los recursos. Hoy, dos tercios de los habitantes del planeta vive en ciudades y toma de la naturaleza los materiales que necesita para construir hogares, escuelas, hospitales, carreteras, sistemas de transporte y fábricas. En el siglo XX se excavó, cortó, perforó o cosechó 34 veces más materiales de construcción, 27 veces más minerales, 12 veces más combustibles fósiles y 3.6 más biomasa que en los años anteriores ${ }^{57}$.

Hasta que el ambiente no forme parte de la sangre, del corazón y de la mente de cada ser humano de este hermoso y único país, se tendrá que seguir creando marcos regulatorios, lo frustrante es que las políticas públicas y la normativa ambiental no serán implementadas o solo se hará parcialmente, por diversas razones: no hay presupuesto, no hay personal, no hay condiciones políticas o sociales, no hay interés, falta conocimiento... Siempre habrá excusas.

Es difícil aprender sino se evalúa constantemente el accionar y, al no identificar y reconocer los errores, estos son recurrentes. Tampoco evaluar desde la lógica de buscar al culpable tiene sentido, hay que ver el fondo, más que la forma. El desarrollo de instrumentos en un vacío de compromiso individual y social con la protección del ambiente se vuelve un intento vano en muchos momentos y con resultados limitados

\footnotetext{
55 «QQué es la economía circular y cómo cuida del medio ambiente?», Programa de las Naciones Unidas para el Desarrollo, acceso: 20 de mayo de 2021, https://news.un.org/es/interview/2018/12/1447801

${ }^{56}$ Roberto Atanasovski, «El desperdicio de comida, una oportunidad para acabar con el hambre», acceso: 19 de mayo de 2021, https://news.un.org/es/story/2018/10/1443382

${ }^{57}$ Ibíd.
} 
en la mayoría de los casos. Todo instrumento requiere un objetivo y su manual de operación, este objetivo y manual debe ser interiorizado y aplicado por cada persona.

Aprender de la historia es fundamental, para no repetirla. Este aprender y reaprender tantas veces como sea necesario, debería llevar a realizar cambios sustantivos de la propia actuación y también de la colectiva. Debería convertir a las personas en defensoras de los derechos ambientales, de manera respetuosa, responsable y oportuna. Debería quitar la ceguera y obligar a tomar conciencia sobre los errores.

Más que alfabetización y consumo de información, acoger una educación ambiental como la que describe el artículo 12 de la Ley Orgánica del Ambiente es urgente. Una educación que lleve a construir, adoptar y perpetuar una cultura ambiental, enfocada en el logro y consolidación de un desarrollo ambientalmente sostenible, sobre una base ecoética. Se debe tomar consciencia, se debe despertar del coma ambiental.

Una educación cuestionadora, reflexiva, transgresora, que supere el paradigma fragmentario y reduccionista, capaz de hacer que las personas vean más que el árbol, que vean el bosque o los bosques. Una educación basada en la certeza de la interdependencia entre diversidad biológica, economía y salud para la vida.

Una educación que haga a la humanidad ser congruente. No se puede seguir predicando un discurso en un lugar y presentando o aceptando discursos contrarios en otros lugares. No es posible que los medios de comunicación, con tanta influencia, estén ajenos de esta educación, así como las empresas ni el gobierno.

Se debe dejar de evadir la investigación, requerida para la toma de decisiones, y la creación de indicadores ambientales que puedan correlacionarse con los sociales y económicos. Lo ambiental no debe ser dejado de lado como último tema de discusión, ni puede dejar de ser financiado porque debe ser lo prioritario, en cada decisión política, social, personal. Tampoco, se deben posponer las decisiones por falta de información, porque en medio de la ignorancia, ya se sabe que causa daño al ambiente. Existe el principio precautorio en el Convenio de Diversidad Biológica y en la Ley de Biodiversidad 7788, proteger la diversidad biológica es la consigna, luego habrá tiempo para «verificar» qué acciones humanas la afectan.

La imagen gráfica del logotipo del bicentenario es reveladora en muchos sentidos. Más de 54 especies de colibríes existen en Costa Rica. De igual forma, en el país existen muchos tipos de personas y pensamientos; pero todos, al igual que los colibríes, dependientes de la biodiversidad para alimentarse y sobrevivir. Igual que estas especies, se debe aportar mucha energía y valor a procesos país, regionales y mundiales.

Los colibríes y las plantas de las que se alimentan tienen una estrecha asociación coevolutiva. La vida de los colibríes está en estrecha relación con la de ciertas plantas y flores; de hecho, constituyen una gran importancia para los ecosistemas, pues son agentes polinizadores de gran cantidad de plantas en los bosques tropicales.

Usar la imagen de un colibrí debería ser, en este bicentenario, el augurio de un cambio de pensamiento individual y colectivo. Cambio que producirá que, más allá de los intereses personales, exista una visión compartida de desarrollo para el aseguramiento de la protección de la naturaleza, asegurar la permanencia de las interrelaciones entre las especies, asegurar la calidad ambiental, para las presentes y futuras generaciones. Esto significa, sin miedo, luchar fuerte e inteligentemente contra las acciones codiciosas y la avaricia, contra las acciones que irrespetan la vida, que atentan contra un $6 \%$ de la biodiversidad reconocida del planeta. 


\section{Figura 3}

Símbolo del bicentenario del Gobierno de Costa Rica 2018-2022
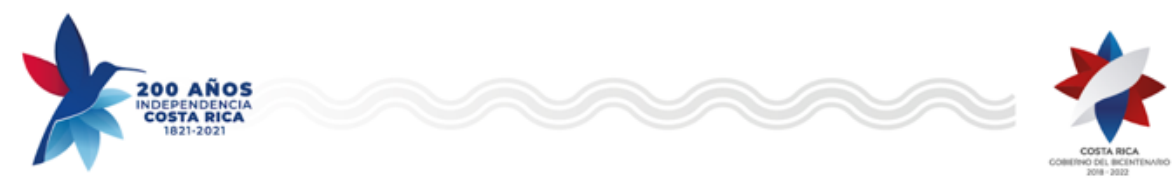

Fuente: Gobierno de Costa Rica, 2021.

Igual que los colibríes, este país -en apariencia, territorialmente pequeño- ha tenido la fuerza para realizar cambios y enrumbar hacia un mejor destino y seguir batiendo las alas, rompiendo las cadenas de modelos opresores que dañan; tomando la misma decisión de hace 200 años, pero en materia ambiental.

La tarea que se enfrenta es ardua, y debe ser prontamente cumplida. En 2010, Costa Rica se comprometió, junto con 195 países, con las 20 metas AICHI es una prefectura de Japón, lugar en que fueron acordadas. El avance que, de acuerdo con el MINAE-SINAC-CONAGEBIO-FONAFIFO ${ }^{58}$ se ha tenido, muestra lo mucho que debe trabajarse, especialmente porque los niveles de conciencia sobre los valores de la biodiversidad muestran ser mínimos y, en consecuencia, lo es la integración de dichos valores (ver Anexo 2).

\section{Epílogo}

En actividades educativas, ocasionalmente se utiliza la técnica de dibujar o describir el hogar que se imagina, que se desea. Este ejercicio debería realizarse como país, para que constituya la hoja de ruta sobre la cual trabajar cada persona en sus diferentes posiciones.

La conservación debe ser parte del desarrollo económico y, este, debe gestionarse sin que atente contra la salud del ambiente y las personas. Cualquier imagen construida conjuntamente, debe estar sobre un lienzo verde, con colores que demuestren la salud ambiental. Una imagen organizada, no improvisada, para un debido monitoreo y evaluación de los impactos, para tener la opción de fortalecer, potenciar o detener y corregir.

Se debe cambiar la práctica política, no ser indiferentes, ser protagonistas del cambio. Este protagonismo se construye desde todos los frentes, si bien es cierto las instituciones educativas formales juegan un papel sustantivo, también lo debe ser la familia, los medios de comunicación, los programas de capacitación y de información. Es una educación para la vida y por la vida. Como bien apuntaba Stephen Covey, «tomar la iniciativa significa reconocer nuestra responsabilidad de hacer que las cosas sucedan ${ }^{59}$.

${ }^{58}$ MINAE-SINAC-CONAGEBIO-FONAFIFO, 2018.

${ }^{59}$ Stephen Covey, Akifrases.com, acceso: 29 de mayo de 2021, https://akifrases.com/frase/200285 
Constantemente se escucha sobre implementar una educación crítica. ¿Qué tan crítica se quiere? ¿Dispuesta a enfrentar y confrontar modelos que favorecen prioritariamente a algunos sectores? La crítica no puede ser selectiva ni conveniente, «la capacidad de dar sentido, de significar el mundo y la propia experiencia pasa por la capacidad de criticar los sentidos y los sinsentidos ajenos. Nada más lejos de la educación, así entendida, que una obediencia ciega a un mando superior» ${ }^{60}$.

Las autoras de este artículo tienen una visión optimista de la vida, sin embargo, la realidad muestra una versión preocupante, crítica, donde la esperanza se asoma apenas en esquinas y con suerte en una calle. No se es pesimista, pero tampoco se quiere ser como muchas personas, que se conforman con lo que tienen porque se comparan con aquellos que no tienen o que tienen poco.

No se puede estar conformes con la dualidad, por un lado, ser referente, galardonado por logros ambientales que han costado mucho; pero por otro lado, con un país donde prevalecen intenciones extractivistas: petróleo, minería, madera, pesca y todo tipo de tráfico de especies, un país sucio, maloliente, con desechos en las calles, ríos, parques, donde todavía las persona no han comprendido que la humanidad hace parte de la naturaleza.

Costa Rica es campeona en muchas formas, pero no se debe ser ciego, también se tiene la cuenca más contaminada de Centroamérica, la del río Grande de Tárcoles, $\mathrm{y}$, contradictoriamente, se cuenta con uno de los ríos más limpios de la región, el Savegre. Se tiene reconocimiento por resguardar más de un $26 \%$ del territorio en alguna categoría de protección; pero increíblemente, para más de 3000 hectáreas solo hay un guardaparque disponible ${ }^{61} \mathrm{y}$, algunos de ellos, han sucumbido ante el COVID-19 en cumplimiento de sus labores.

Si lo que interesa es dinero, «solo en 2016, los Parques Nacionales y las reservas biológicas aportaron un $3 \%$ del PIB, más de US\$ 1800 millones (...) en el 2002 y 2011, aportaron alrededor de un $5 \%$ del PIB, y en el 2002, el aporte en dólares fue de US\$ 814 millones y, en el 2011, fue de US\$ 1300 millones $)^{62}$. Solo en 2017, mediante un proyecto, se logró determinar que siete de los humedales de Costa Rica generan más de US\$ 3 mil millones al año ${ }^{63}$. Sin embargo, estos datos se quedan cortos porque el país aún no contabiliza el aporte real de la naturaleza a la economía y sociedad, no solo del país, sino de la región y del mundo.

\footnotetext{
${ }^{60}$ Francisco Gutiérrez y Daniel Prieto, La mediación pedagógica: apuntes para una educación a distancia alternativa (Guatemala: Universidad de San Carlos, Instituto de Investigaciones y Mejoramiento Educativo, 1993), 37.

${ }^{61}$ Diego Castillo, «Cada guardaparque costarricense debe proteger 3,400 hectáreas de zonas protegidas», Nuestra Voz. Amelia Rueda.com, 12 de febrero de 2017, acceso: 16 de mayo de 2021, https://www.ameliarueda.com/nota/cada-guardaparque-costarricense-proteger-3.400-hectareas-zonasprotegidas

${ }^{62}$ Sebastián Rodríguez, «Parques Nacionales y Reservas Biológicas aportarán más de $3 \%$ del PIB en el 2016», acceso: 20 de mayo de 2021, https://ojoalclima.com/parques-nacionales-y-reservasbiologicas-aportaron-mas-de-3-del-pib-en-el-2016/

${ }^{63}$ PNUD, «Siete humedales generan más de US\$3 mil millones al país cada año», Programa de las Naciones Unidas para el Desarrollo, acceso el 20 de mayo de 2021, https://www.cr.undp.org/content/costarica/es/home/presscenter/pressreleases/2017/08/31/sietehumedales-generan-m-s-de-us-3-mil-millones-al-pa-s-cada-a-o.html. Estudio del CINPE-UNA para el Proyecto Humedales del SINAC-PNUD-GEF cuantificó el valor de los servicios ecosistémicos de siete humedales de importancia internacional del país: Palo Verde, Las Baulas, Caribe Noreste, Caño Negro, Gandoca-Manzanillo, Maquenque y Térraba-Sierpe.
} 
Pero cuidado, la vida merece estar presente, el ser humano no tiene derecho a decidir sobre la gran variedad de seres vivos, se es uno más de ellos; una visión antropocéntrica como la que se está padeciendo, arrastra a la extinción.

Formamos parte de la red de la vida, como seres vivientes, al igual que las hormigas, los delfines, las dantas y cada una de las especies con las cuales se comparte el planeta ¿Se ha alejado tanto la humanidad de su origen y de la dependencia de la vida? ¿Tanta es la distancia, que no se cree necesitar la tierra, el agua y el aire? Si en algo hay diferencia, es en la responsabilidad que se tiene para construir o destruir, ninguna de las otras especies ha sido letal. Si se tiene la característica de crear cultura, de apreciar las formas de aprender y multiplicar los aprendizajes, ¿Por qué no se hace del mundo un lugar limpio, habitable, amoroso, bello?

Necesitamos apostar y ejecutar un proceso reflexivo y honesto sobre las actuaciones propias, sobre el accionar de la familia, de la comunidad, de las empresas, de los grupos sociales organizados, de los medios, de los políticos, de la academia, en un proceso permanente. Pero no quedarse en la reflexión, debemos actuar, cambiar y tener el valor para hacerlo. Para quien el cambio es más difícil, sea por falta de conocimiento, por falta de interés o porque es víctima de los modelos de economías ambientalmente no sostenibles, debemos en conjunto, ayudar a encontrar formas para estar mejor.

Realizar una educación que busque, como bien indicaban Gutiérrez y Prieto ${ }^{64}$, «cómo educar para la incertidumbre, para gozar de la vida, para significar y expresar el mundo, para convivir solidariamente y para apropiarse de la historia y de la cultura». Todos somos responsables de esta educación, porque se educa con las actuaciones, mediante capacitaciones, mediante publicaciones, mediante conversaciones, mediante programas y proyectos, mediante las decisiones.

Rescatar la historia y basar en ella el desarrollo de programas educativos, formales, informales o no formales, es una tarea obligada. Allí se encuentran respuestas sobre qué era bueno y qué no para la protección de la diversidad biológica, para un desarrollo ambientalmente sostenible. Se habla más que de alfabetizar, de estimular personas lectoras e investigadoras asiduas, que se nutran grupalmente, esto significa que el individualismo debe abandonar los espacios, se está hablando de un futuro común. Si los modelos que están siendo exportados no satisfacen esta intención, se deben desechar.

Nadie nos educa para vivir en la incertidumbre, solo la vida se encarga de ello, y ¡a qué precio!, sobre todo para quienes carecen de recursos que permitan hacerle frente (...). En manos de la mayoría de las instituciones sociales, ella se convierte en el esfuerzo de lograr la ilusión de certidumbre, sea a través de sistemas pedagógicos condicionados y condicionantes, de salidas políticas mágicas, de propuestas utópicas. ${ }^{65}$

Hay que educar para la incertidumbre, todos y cada uno, haciendo realidad la educación de la que tanto habló Gutiérrez y Prieto ${ }^{66}$. Hay que eliminar de la práctica el paradigma de la certeza porque es falso, lo más constante es el cambio. Se debe presionar al Estado, a los medios de comunicación, a cada vecino, a centros educativos, porque de este tipo de educación depende la salud integral; no se habla

\footnotetext{
${ }^{64}$ Gutiérrez y Prieto, La mediación pedagógica..., 170.

${ }^{65}$ Ibíd., 30-31.

66 Ibíd.
} 
de ausencia de enfermedad, sino de salud física, mental y espiritual. Así, como todo educa, todo enseña, desde cada posición se debería:

- Crear, recrear y utilizar recursos tecnológicos.

- Localizar, reconocer, procesar y utilizar información.

- Interrogar en forma permanente. No enseñar ni inculcar respuestas.

- Saber reconocer las propuestas mágicas de certidumbre, para desmitificarlas y resignificarlas. No hacer más de lo mismo, lo que no ha funcionado, excepto para alargar más la solución efectiva.

- Resolver problemas. Siempre que se pueda, ser actores y actrices, no observadores de la propia destrucción.

Para las personas educadoras, en lo formal, no formal e informal (la vida cotidiana) se deben hacer propias las palabras de Gutiérrez y Prieto ${ }^{67}$, «una educación con sentido educa protagonistas, seres para los cuales todas y cada una de las actividades, todos y cada uno de los conceptos, todos y cada uno de los proyectos, significan algo para su vida. Es esa significación el punto de partida de la significación del mundo, y de los demás». Nada más contrario a lo que aplican muchos docentes, que procuran inyectar respuestas, brindar la verdad absoluta, guiar sobre conocimientos mejores según las normas impuestas por otros, tener buenos estudiantes que constituyen excelentes receptáculos de lo enseñado, que logran expulsar a conveniencia del sistema. Una transformación requiere personas ingeniosas, un sistema social coercitivo parece no ser el mejor medio de cultivo para crearlas.

Hay que dejar de culpar a las demás personas e instituciones, se debe empezar el cambio, recordemos que el cambio inicia en mí, en usted. Con una presión respetuosa a favor del cambio de las instituciones que deben asegurar el bien público. Hay que exponer, en los medios adecuados, a quienes atentan contra la conservación de biodiversidad (personas, organizaciones, medios de comunicación, empresas). Se debe enfrentar a quienes ganan a costa del daño ambiental, solo por dinero, y apoyar a aquellos que, además de ganar, invierten en el futuro de este bello país.

La reflexión sobre la acción debe ser la constante, así como la búsqueda de información para resolver y salvaguardar la biodiversidad. Rechazar es el primer paso, rechazar lo que contamina, lo que hace daño, lo que se acumula y no se elimina, rechazar lo que no resuelve el problema y solo lo amortigua. Rescatar lo que funciona y utilizarlo ¿De qué sirve el artículo 50 de la Constitución si no se aplica, o bien, la Ley Orgánica del Ambiente, la Ley de Biodiversidad?

Las políticas públicas y la legislación son instrumentos. Se debe aprender cómo se aplican y cuándo aplicarlos para la autodefensa. Los instrumentos deben ser utilizados por quienes aman su país, deben ser conocidos desde la más tierna infancia, así como los mecanismos para su implementación. Se debe pasar de las letras a la aplicación, sin desconocer diferentes realidades y procurando el mayor bienestar «para todas las personas», no para unas cuantas.

Hay que agradecer cada día por ser parte de este extraordinario milagro de la biodiversidad, tomarse unos minutos diarios para contemplar la extraordinaria grandeza de la que somos parte, conectarse a través del oxígeno, el agua, la tierra; presenciar la conexión con todos lo seres, recordando a James Lovelock y su

\footnotetext{
${ }^{67}$ Ibíd., 37.
} 
hipótesis de Gaia, que se sustenta en el reconocimiento de que la Tierra es más que una casa, sino que es un sistema vivo del cual somos una parte. Cuando se vaya de compras, hay que pensar en el origen de lo que se consume y ¿Qué se va a hacer con ese alimento, objeto o producto? ¿Qué aporta a la vida, a la forma de ser y estar de cada quien? ¿En qué se transformará?

Todas las personas estamos implicadas y somos corresponsables, nadie escapa, teniendo presente que, a mayor responsabilidad, mayor impacto; eso significa reconocer que hay escalas de responsabilización. Se debe dejar de planificar tanto y actuar más. Se debe dejar de hablar tanto, dejar de crear discursos cansados que alimentan egos. Se debe dejar de temer y trabajar en favor de la supervivencia. El país no puede seguir a la deriva, el futuro se construye cada día, no es un tema puntual ni de moda, es un propósito de vida proteger la naturaleza.

Hay que aprender a defender el derecho a un ambiente sano y ecológicamente equilibrado, practicar todos los días y, entre más se practique, se construirá una cultura ambiental. Que el tiempo que se esté en este país y este planeta sea de calidad, sea de cuido mutuo, sea de respeto, de confianza y alegría.

La interdependencia de la red de la vida es innegable como se ha podido apreciar, sin embargo, en materia ambiental hay que hacer acción y realidad las palabras independencia y libertad. Independencia para elegir la forma de vivir en concordancia con una educación permanente a favor de los ciclos de la vida y esta solo puede hacerse en libertad, la complejidad es consustancial con lo vital.

Como bien indica el comunicado de celebración del Día Mundial del Ambiente ${ }^{68}$, «No podemos volver el tiempo atrás. Pero podemos cultivar árboles, reverdecer nuestras ciudades, repoblar nuestros jardines con especies silvestres, cambiar nuestras dietas y limpiar ríos y costas. Somos la generación que puede hacer las paces con la naturaleza (...)». No hay que rendirse, por el contrario, restaura, reimagina, reinventa ${ }^{69}$.

Los buenos planetas son difíciles de encontrar. No todo está perdido, si se puede hacer mucho daño, también se puede hacer mucho bien. La decisión es suya, es nuestra.

Formato de citación según APA

Roldán-Chacón, C. A. y Peña-Vargas, V. (2021). ¿Un bicentenario ambientalmente sostenible? Revista Espiga, 20 (42), 86-120.

Formato de citación según Chicago-Deusto

Roldán-Chacón, Carmen Alexa y Peña-Vargas, Vilma. «¿Un bicentenario ambientalmente sostenible?». Revista Espiga 20, n. ${ }^{\circ} 42$ (setiembre, 2021): 86-120.

\footnotetext{
${ }^{68}$ Inspirado en el comunicado del Día Mundial del Ambiente 2021 de las Naciones Unidas, https://www.worldenvironmentday.global/es

69 Ibíd.
} 


\section{Referencias}

Abram, David. La magia de los sentidos. Barcelona: Editorial Kairós, 2000.

Álvarez, Mauricio. «Daños ambientales generados por la construcción de la carretera 1856. Agua en Centroamérica: Oportunidades para la solución de conflictos»». Costa Rica, 2012. Disponible en: http://ragua.com/wpcontent/uploads/2012/12/impactos-ambientales-de-la-trochafronterizaMauricio-Alvarez.pdf

Archivo Nacional de Costa Rica. «Costa Rica comienza el camino de la conmemoración de sus 200 años de independencia», Costa Rica, 2021. Disponible: en:

https://www.archivonacional.go.cr/index.php/component/content/article/128 -noticias/246-costa-rica-comienza-el-camino-de-la-conmemoracion-de-sus200 -anos-de-independencia? Itemid $=437$

Atanasovski, Roberto. «El desperdicio de comida, una oportunidad para acabar con el hambre». Noticias ONU. Mirada global. Historias humanas. Acceso: $19 \mathrm{de}$ mayo de 2021. https://news.un.org/es/interview/2018/12/1447801

Castillo, Diego. «Cada guardaparque costarricense debe proteger 3400 hectáreas de zonas protegidas». Nuestra voz. Amelia Rueda.com, 12 de febrero de 2017. Acceso: 16 de mayo de 2021. https://www.ameliarueda.com/nota/cadaguardaparque-costarricense-proteger-3.400-hectareas-zonas-protegidas

Chacón Araya, Karen. «Agricultura y sostenibilidad ambiental en Costa Rica». En Investigación de base para le Informe del Estado de la Nación, editado por Estado de la Nación. San José: Programa Estado de la Nación, 2019. https://www.binasss.sa.cr/opac-

$\mathrm{ms} /$ media/digitales/Agricultura $\% 20 \mathrm{y} \% 20$ sostenibilidad $\% 20$ ambiental $\% 20$ en \%20Costa\%20Rica.pdf

De Saint-Exupéry, Antoine. El Principito. México: Editores Mexicanos Unidos, S. A., 2001.

Fischlin Andreas, G.F. Midgley, Jeff Price, Rik Leemans, Brij Gopal. «Ecosystems, their properties, goods and services». En: Climate change 2007: impacts, adaptation and vulnerability. Contribution of working group II to the fourth assessment report of the intergovernmental panel on climate change (IPCC). Cambridge: Cambridge University Press, 2007.

Fournier Origgi, Luis. Desarrollo y perspectivas del movimiento conservacionista costarricense. San José: Editorial Universidad de Costa Rica, 1991.

Garza, Jeffrey. «Costa Rica desaprovecha su potencial en apicultura». La República, 5 de febrero de 2021. Acceso: 22 de mayo de 2021. https://www.larepublica.net/noticia/costa-rica-desaprovecha-su-potencial-enapicultura 
Gobierno de Costa Rica. Constitución Política de la República de Costa Rica. San José: República de Costa Rica, 1949.

https://www.pgrweb.go.cr/scij/Busqueda/Normativa/Normas/nrm_texto_co mpleto.aspx?nValor $1=1 \&$ nValor $2=871$

Gobierno de Costa Rica. Ley Forestal No.7032. San José: Asamblea Legislativa, 1986.

http://www.pgrweb.go.cr/scij/Busqueda/Normativa/Normas/nrm_texto_com pleto.aspx?param $1=$ NRTC $\&$ nValor $1=1 \&$ nValor $2=8072 \&$ nValor3 $=90679 \& p$ $\operatorname{aram} 2=1 \& \operatorname{strTipM}=\mathrm{TC} \& 1$ Resultado $=6 \& \operatorname{strSim}=\operatorname{sim} p$

Gobierno de Costa Rica. Ley forestal No.7575. San José: Asamblea Legislativa, 1996.

http://www.pgrweb.go.cr/scij/Busqueda/Normativa/Normas/nrm_texto_com pleto.aspx?param $1=$ NRTC \&nValor $1=1 \&$ nValor $2=41661 \&$ nValor $3=124525$ \&param $2=1 \&$ strTipM $=$ TC\&1Resultado $=1 \&$ strSim $=$ simp

Gobierno de Costa Rica. Ley Orgánica del Ambiente No.7554. San José: Asamblea Legislativa, 1995. http://www.pgrweb.go.cr/scij/Busqueda/Normativa/Normas/nrm_texto_com pleto.aspx?param $1=$ NRTC\&nValor $1=1 \&$ nValor $2=27738 \& n$ Valor $3=116998$ \&param $2=1 \&$ strTipM $=$ TC\&1Resultado $=5 \& \operatorname{str} \operatorname{Sim}=\operatorname{simp}$

Gobierno de Costa Rica. Ley de Conservación de la Vida Silvestre No.7317. San José: Asamblea Legislativa, 1992.

http://www.pgrweb.go.cr/scij/Busqueda/Normativa/Normas/nrm_texto_com pleto.aspx?param $1=$ NRTC\&nValor $1=1 \&$ nValor $2=12648 \&$ nValor3=122136 \&param $2=1 \&$ strTipM $=$ TC\&1Resultado $=9 \&$ strSim $=$ simp

Gutiérrez, Francisco y Daniel Prieto. La mediación pedagógica: apuntes para una educación a distancia alternativa. Guatemala: Universidad de San Carlos, Instituto de Investigaciones y Mejoramiento Educativo, 1993.

MINAE. Situación de la explotación ilegal de oro en Crucitas y las afectaciones ambientales asociadas. Costa Rica: MINAE, 2020. Disponible en http://d1qqtien6gys07.cloudfront.net/wp-content/uploads/2020/03/DM0154-2020-Informe-sobre-Crucitas.pdf

MINAE-SINAC-CONAGEBIO-FONAFIFO. Resumen del Sexto Informe Nacional de Costa Rica ante el Convenio de Diversidad Biológica. San José: Programa de Naciones Unidas para el Desarrollo. Apoyo técnico para que las Partes Elegibles desarrollen el Sexto Informe Nacional para el CDB (6NR-LAC), Costa Rica, 2018. https://www.cbd.int/doc/nr/nr-06/cr-nr-06-p2-es.pdf

Obando Vargas, German y Mariela Obando Coronado. Costa Rica uso del suelo: Tras el fin de la deforestación, estrategias y acciones para el uso sostenible de la tierra. San José: Climate Chance, 2020. https://www.climatechance.org/wp-

content/uploads/2020/09/costarica_usodelsuelo_climatechance_espa.pdf 
O’neal Coto, Katzy. «UCR advirtió presencia de plaguicida usado en piña en Humedal Térraba-Sierpe». UCR Noticias. Acceso: 20 de mayo de 2021. https:/www.ucr.ac.cr/noticias/2017/05/15/ucr-advirtio-presencia-deplaguicida-usado-en-pina-en-humedal-terraba-sierpe.html

O'neal Coto, Katzy. «UCR detecta residuos de plaguicidas en fuentes de agua en la Zona Norte». UCR Noticias. Acceso: 20 de mayo de 2021. https://www.ucr.ac.cr/noticias/2018/06/14/ucr-detecta-residuos-deplaguicidas-en-fuentes-de-agua-en-la-zona-norte.html

O'neal Coto, Katzy, «El problema ambiental más grave de Costa Rica es el consumo». UCR Noticias. Acceso: 20 de mayo de 2021. https://www.ucr.ac.cr/noticias/2019/07/16/el-problema-ambiental-masgrave-en-costa-rica-es-el-consumo.html

Pratesi, Isabella, Marco Galavarni, Marco Antonelli, Mar Asunción, Lennys Rivera y Luis Suárez. Pérdida de naturaleza y pandemias. Un planeta sano por la salud de la humanidad. Madrid: WWF España, 2020.

https://wwfes.awsassets.panda.org/downloads/naturaleza_y_pandemias_wwf .pdf

Programa de las Naciones Unidas para el Desarrollo. «¿Qué es la economía circular y cómo cuida del medio ambiente?». Acceso: 20 de mayo de 2021. https://news.un.org/es/interview/2018/12/1447801

Programa de las Naciones Unidas para el Desarrollo. «Siete humedales generan más de US\$3 mil millones al país cada año». Acceso: 20 de mayo de 2021. https://www.cr.undp.org/content/costarica/es/home/presscenter/pressreleases /2017/08/31/siete-humedales-generan-m-s-de-us-3-mil-millones-al-pa-scada-a-o.html

Quesada Pacheco, Miguel Ángel. Entre silladas y rejoyas. Viajeros por Costa Rica de 1850 a 1950. Cartago: Editorial Tecnológica de Costa Rica, 2001.

Rodríguez, Sebastián. «Parques Nacionales y Reservas Biológicas aportaron más de 3\% del PIB en el 2016». Ojo al Clima. Acceso: 20 de mayo de 2021. https://ojoalclima.com/parques-nacionales-y-reservas-biologicas-aportaronmas-de-3-del-pib-en-el-2016/

Servicio Fitosanitario del Estado SFE. Informe del año 2018 sobre análisis de residuos de plaguicidas en vegetales frescos en costa rica de producción nacional e intención de importación. San José: MAG. Unidad de Control de Residuos Químicos. Servicio Fitosanitario del Estado (2018). https://www.sfe.go.cr/DocsResiduosAgroquim/Informe $\% 20$ sobre $\% 20$ residu os\%20de\%20plaguicidas\%202018.pdf

Servicio Fitosanitario del Estado. MAG-Costa Rica. «Registro de Agricultura Orgánica (ARAO). Acceso: 16 de mayo de 2021. https://www.sfe.go.cr/SitePages/ARAO/InicioARAO.aspx

Skutch, Alexander. La finca de un naturalista. San José: Editorial Costa Rica, 1985. 
Tjader, Agneta. «Olof Wessberg y Karen Mogensen: gestores de la creación de la Reserva Natural Absoluta Cabo Blanco». Revista Biocenosis 28, n. ${ }^{\circ}$ 1-2 (2014): 38-43 (2014).

https://revistas.uned.ac.cr/index.php/biocenosis/article/view/807

Universidad de Costa Rica. «La Universidad de Costa Rica respondió a las consultas de los diputados sobre los plaguicidas». Noticias UCR. Acceso: 20 de mayo 2021. https://www.ucr.ac.cr/noticias/2018/07/20/la-universidad-decosta-rica-respondio-a-las-consultas-de-los-diputados-sobre-losplaguicidas.html 


\section{Anexo 1}

Tendencias de elementos de la biodiversidad, pérdida, estabilidad o recuperación, de acuerdo con el VI Informe País para el Convenio de Diversidad Biológica.

\begin{tabular}{|c|c|c|c|}
\hline Nivel & $\begin{array}{l}\text { Elemento de la } \\
\text { biodiversidad }\end{array}$ & $\mathrm{T}$ & Observaciones \\
\hline \multirow{6}{*}{ Paisajes } & $\begin{array}{l}\text { Cobertura forestal } \\
\text { (bosque, plantaciones, } \\
\text { pastos arbolados) }\end{array}$ & $\rightarrow$ & $\begin{array}{l}75,5 \% \text { del territorio terrestre sin disminución } \\
\text { (Emanuelli et al. 2015, Programa Estado de la } \\
\text { Nación, 2017). }\end{array}$ \\
\hline & $\begin{array}{l}\text { Cobertura bosques (solo } \\
\text { bosques naturales) }\end{array}$ & $\uparrow$ & $\begin{array}{l}52,4 \% \text { territorio terrestre (PEN, 2017), según los } \\
\text { expertos consultados se espera que para } 2020 \text { la } \\
\text { cobertura se elevará al } 61 \% \text {. (Nota: de acuerdo con } \\
\text { el Plan Nacional de Descarbonización se espera un } \\
60 \% \text { de cobertura para el } 2030 \text { ). }\end{array}$ \\
\hline & $\begin{array}{l}\text { Conectividad estructural } \\
\text { de paisajes }\end{array}$ & $\uparrow$ & $\begin{array}{l}59 \% \text { área } \mathrm{CB} \text { índice de biodiversidad mayor a la } \\
\text { media y el } 63 \% \text { área } \mathrm{CB} \text { índice de resistencia menor } \\
\text { de } 200 \text { (PCB, 2018). }\end{array}$ \\
\hline & $\begin{array}{l}\text { Paisajes forestales } \\
\text { intactos }\end{array}$ & $\downarrow$ & $\begin{array}{l}\text { Disminución del } 2 \% \text { entre 2000-2016 (Patapov et al. } \\
\text { 2008). }\end{array}$ \\
\hline & $\begin{array}{l}\text { Ecosistemas protegidos } \\
\text { terrestres }\end{array}$ & $\rightarrow$ & $\begin{array}{l}26 \% \text { del territorio terrestre sin disminución (SINAC, } \\
2018 \text { ). }\end{array}$ \\
\hline & $\begin{array}{l}\text { Ecosistemas protegidos } \\
\text { marinos }\end{array}$ & $\uparrow$ & $\begin{array}{l}2,75 \% \text { del territorio marino (ZEE), creación de } \\
\text { nuevas áreas marinas protegidas en 2014-2018 } \\
\text { (SINAC, 2018). }\end{array}$ \\
\hline \multirow{3}{*}{$\begin{array}{l}\text { Ecosiste } \\
\text { mas } \\
\text { terrestres }\end{array}$} & Bosque seco tropical & $\uparrow$ & $\begin{array}{l}\text { Recuperación en la última década (Kappelle, 2016; } \\
\text { Janzen \& Hallwachs, 2016; Nasa Project - Huella } \\
\text { humana, 2018); sin embargo, expertos consultados } \\
\text { indican que existen evidencias sobre los efectos } \\
\text { negativos del cambio climático que ha ocasionado } \\
\text { muertes masivas de árboles. }\end{array}$ \\
\hline & Bosque húmedo tropical & $\downarrow$ & $\begin{array}{l}\text { Deforestación agroindustrial (Sierra, et al., 2016; } \\
\text { MINAE, 2018); expertos consultados reportan } \\
\text { efectos negativos del cambio climático, disminución } \\
\text { drástica en población de invertebrados en general. }\end{array}$ \\
\hline & Bosque montano & $\rightarrow$ & $\begin{array}{l}\text { Niveles de deterioro de bajos a moderados (SINAC, } \\
\text { 2014). }\end{array}$ \\
\hline \multirow{3}{*}{$\begin{array}{l}\text { Ecosiste } \\
\text { mas } \\
\text { costero- } \\
\text { marinos } \\
\text { y } \\
\text { humedal } \\
\text { es }\end{array}$} & Páramo & $\rightarrow$ & Sin datos. \\
\hline & Manglar & $\downarrow$ & $\begin{array}{l}\text { Afectación por aumento del nivel del mar, } \\
\text { sedimentación y desecación (Unión Europea, en } \\
\text { prep.). }\end{array}$ \\
\hline & Arrecifes & $\downarrow$ & $\begin{array}{l}\text { Afectación por aumento de temperatura de los } \\
\text { océanos, aumento del nivel del mar, acidificación, } \\
\text { sedimentación, pesca insostenible (SINAC, 2016; } \\
\text { Cortés, 2016; Bellwood et al. 2004, Fonseca et al. } \\
\text { 2006, Mumby 2009, Hughes et al. 2010, ACT- }\end{array}$ \\
\hline
\end{tabular}




\begin{tabular}{|c|c|c|c|}
\hline Nivel & $\begin{array}{l}\text { Elemento de la } \\
\text { biodiversidad }\end{array}$ & $\mathrm{T}$ & Observaciones \\
\hline & & & $\begin{array}{l}\text { SINAC, 2017; Arana et al, 2013; Clarke et al 2018, } \\
\text { Espinoza et al, 2018). }\end{array}$ \\
\hline & Pastos marinos & $\downarrow$ & $\begin{array}{l}\text { Afectación por aumento de temperatura de los } \\
\text { océanos, aumento del nivel del mar, acidificación, } \\
\text { sedimentación (SINAC, 2016). }\end{array}$ \\
\hline & Playas arenosas & $\downarrow$ & $\begin{array}{l}\text { Afectación por aumento del nivel del mar y procesos } \\
\text { erosivos, pesca insostenible, sobrecarga de la } \\
\text { visitación turística, sedimentación, infraestructura } \\
\text { (SINAC, 2016). }\end{array}$ \\
\hline & Lagunas & $\downarrow$ & $\begin{array}{l}\text { Afectación por sedimentación, eutrofización, } \\
\text { desecación (Programa Humedales, SINAC, 2018); } \\
\text { expertos consultados agregan que hay un cambio de } \\
\text { tipo de humedal lacustre o palustre por } \\
\text { sedimentación y desecación (Inventario Nacional de } \\
\text { Humedales, 2018). }\end{array}$ \\
\hline & Pantanos & $\downarrow$ & $\begin{array}{l}\text { Afectación por sedimentación, eutrofización, } \\
\text { drenajes, rellenos, fuegos y contaminación } \\
\text { (Programa Humedales, SINAC, 2018); expertos } \\
\text { consultados evidencian procesos de desecación y } \\
\text { sedimentación en los pantanos o sistemas palustres } \\
\text { de zona Norte y Caribe Norte (Inventario Nacional } \\
\text { de Humedales, 2018). }\end{array}$ \\
\hline & Ríos & $\rightarrow$ & $\begin{array}{l}\text { Expertos consultados indican que si bien los cuerpos } \\
\text { de agua terrestres presentan afectaciones por } \\
\text { sedimentación y contaminación (MINAE, 2018), y } \\
\text { otras vinculadas con los efectos esperados del } \\
\text { cambio climático, en general la tendencia de estos } \\
\text { ecosistemas es a mantenerse. }\end{array}$ \\
\hline & Océanos y mares & $\uparrow$ & $\begin{array}{l}\text { Expertos consultados indican una mejora en los } \\
\text { ecosistemas oceánicos debido a los esfuerzos de } \\
\text { conservación realizados con la ampliación de las } \\
\text { AMP y la Plataforma de grandes pelágicos. }\end{array}$ \\
\hline & Plantas & $\begin{array}{l}\mathrm{s} / \\
\mathrm{d}\end{array}$ & $\begin{array}{l}\text { Sin datos; expertos consultados no acuerdan una } \\
\text { tendencia general para el grupo. }\end{array}$ \\
\hline Especies & $\begin{array}{l}\text { Celenterados o } \\
\text { Cnidarios } \\
\text { (corales) }\end{array}$ & $\downarrow$ & $\begin{array}{l}\text { En descenso excepto en sitios específicos como } \\
\text { Golfo Dulce, donde la principal formación coralina } \\
\text { (Sándalo) ha mostrado recuperación importante. } \\
\text { Continúa el aumento en la temperatura del agua, así } \\
\text { como la sedimentación costera. Adicionalmente, } \\
\text { también la contaminación por plásticos y la } \\
\text { competencia por cobertura con el alga invasora } \\
\text { Caulerpa sp. (Alvarado, CIMAR-UCR, com. pers. } \\
\text { 2018). }\end{array}$ \\
\hline
\end{tabular}




\begin{tabular}{|c|c|c|c|}
\hline Nivel & $\begin{array}{l}\text { Elemento de la } \\
\text { biodiversidad }\end{array}$ & $\mathrm{T}$ & Observaciones \\
\hline & $\begin{array}{l}\text { Anélidos (Poliquetos: } \\
\text { gusanos marinos) }\end{array}$ & $\rightarrow$ & $\begin{array}{l}\text { No hay información disponible, aunque el hábitat de } \\
\text { la mayoría de las especies se ha deteriorado, los } \\
\text { expertos acuerdan que el grupo permanece estable. }\end{array}$ \\
\hline & Moluscos & $\rightarrow$ & $\begin{array}{l}\text { Expertos consultados indican que el grupo } \\
\text { permanece estable en general, pero presenta una } \\
\text { disminución de poblaciones en las especies de valor } \\
\text { comercial. }\end{array}$ \\
\hline & Crustáceos & $\rightarrow$ & $\begin{array}{l}\text { Expertos consultados indican que el grupo } \\
\text { permanece estable en general, pero presenta una } \\
\text { disminución de poblaciones en las especies de valor } \\
\text { comercial. }\end{array}$ \\
\hline & Equinodermos & $\rightarrow$ & $\begin{array}{l}\text { Expertos consultados indican que hay poca } \\
\text { información disponible, aunque en general el grupo } \\
\text { permanece estable, pero se considera que su hábitat } \\
\text { se ha deteriorado. }\end{array}$ \\
\hline & Peces cartilaginosos & $\downarrow$ & $\begin{array}{l}\text { Expertos consideran que es el grupo marino más } \\
\text { impactado y amenazado en forma directa por las } \\
\text { actividades humanas, y presentan muchas } \\
\text { poblaciones en descenso. }\end{array}$ \\
\hline & Peces óseos & $\rightarrow$ & $\begin{array}{l}\text { Expertos consultados indican que el grupo } \\
\text { permanece estable en general, pero con poblaciones } \\
\text { de corvina reina (Cynoscion albus) y del pez espada } \\
\text { (Xiphias gladius) en descenso. Disminución en } \\
\text { capturas (Espinoza, } 2017 \text { y MINAE, 2018). }\end{array}$ \\
\hline & Anfibios & $\downarrow$ & $\begin{array}{l}\text { Disminución de poblaciones, aumento de especies } \\
\text { amenazadas (PEN, 2017, Lista Roja IUCN, 2018). }\end{array}$ \\
\hline & Reptiles & $\begin{array}{l}\mathrm{s} / \\
\mathrm{d}\end{array}$ & $\begin{array}{l}\text { Disminución de poblaciones, aumento de especies } \\
\text { amenazadas (PEN, 2017, Lista Roja IUCN, 2018); } \\
\text { expertos consultados no acuerdan una tendencia } \\
\text { general para el grupo. }\end{array}$ \\
\hline & Aves & $\downarrow$ & $\begin{array}{l}\text { Disminución de poblaciones, aumento de especies } \\
\text { amenazadas (PEN, 2017, Lista Roja IUCN, 2018); } \\
\text { expertos consultados reportan que el } 50 \% \text { especies } \\
\text { en Centro América están calificadas como } \\
\text { vulnerables. }\end{array}$ \\
\hline & Mamíferos & $\downarrow$ & $\begin{array}{l}\text { Disminución de poblaciones, aumento de especies } \\
\text { amenazadas (PEN, 2017, Lista Roja IUCN, 2018). }\end{array}$ \\
\hline \multirow{2}{*}{$\begin{array}{l}\text { Agro- } \\
\text { ecosistem } \\
\text { as }\end{array}$} & Banano & $\uparrow$ & $\begin{array}{l}\text { Incremento en el área dedicada a cultivos } \\
\text { permanentes, vinculados con productos de } \\
\text { exportación (FAO, 2018, INEC, 2014, PEN, 2017). }\end{array}$ \\
\hline & Acuicultura & $\rightarrow$ & \\
\hline
\end{tabular}




\begin{tabular}{|l|l|l|}
\hline Nivel $\begin{array}{l}\text { Elemento de la } \\
\text { biodiversidad }\end{array}$ & $\mathrm{T}$ & Observaciones \\
\hline Piña & $\uparrow$ & $\begin{array}{l}\text { Incremento en el área dedicada a cultivos } \\
\text { permanentes, vinculados con productos de } \\
\text { exportación (FAO, 2018, INEC, 2014, PEN, 2017). }\end{array}$ \\
\hline Arroz & $\rightarrow$ & (FAO, 2018, INWC, 2014, PEN, 2017). \\
\hline Caña de azúcar & $\downarrow$ & $\begin{array}{l}\text { Disminución del 10\% del área dedicada al cultivo } \\
\text { (SEPSA 2017, FAO, 2018, INEC, 2014, PEN, }\end{array}$ \\
& $\begin{array}{l}\text { 2017). } \\
\text { Palma aceitera }\end{array}$ & $\begin{array}{l}\text { Incremento en el área dedicada a cultivos } \\
\text { permanentes, vinculados con productos de } \\
\text { exportación (FAO, 2018, INWC, 2014, PEN, 2017). }\end{array}$ \\
\hline Pastos & $\downarrow$ & $\begin{array}{l}\text { Se reporta disminución en las áreas destinadas a la } \\
\text { ganadería (FAO, 2018, MINAE,2018, PEN, 2017). }\end{array}$ \\
\hline
\end{tabular}

Fuente: MINAE (2018). 


\section{Anexo 2}

Metas AICHI versus el porcentaje de avance promedio de Costa Rica.

El color destacado es llamando la atención en algunos ítem por el casi nulo avance.

\begin{tabular}{|c|c|c|c|c|c|c|c|}
\hline $\begin{array}{l}\text { Meta AICHI versus } \\
\text { porcentaje de } \\
\text { avance promedio }\end{array}$ & $\begin{array}{l}\text { Meno } \\
\text { r a } 10 \\
\%\end{array}$ & $\begin{array}{l}\text { Meno } \\
\text { r a } 20 \\
\%\end{array}$ & $\begin{array}{l}\text { Meno } \\
\text { r a } 30 \\
\%\end{array}$ & $\begin{array}{l}\text { Meno } \\
\text { r a } 40 \\
\%\end{array}$ & $\begin{array}{l}\text { Meno } \\
\text { r a } 50 \\
\%\end{array}$ & $\begin{array}{l}\text { Meno } \\
\text { r a } 60 \\
\%\end{array}$ & $\begin{array}{l}\text { Meno } \\
\text { r a } 70 \\
\%\end{array}$ \\
\hline $\begin{array}{l}\text { 1) Concienciaci } \\
\text { ón de los valores de la } \\
\text { biodiversidad }\end{array}$ & & & & & & & \\
\hline $\begin{array}{l}\text { 2) Integración } \\
\text { de los valores de la } \\
\text { biodiversidad }\end{array}$ & & & & & & & \\
\hline $\begin{array}{l}\text { 3) Incentivos } \\
\text { negativos y positivas }\end{array}$ & & & & & & & \\
\hline $\begin{array}{l}\text { 4) Producción y } \\
\text { consumo sostenibles }\end{array}$ & & & & & & & \\
\hline $\begin{array}{l}\text { 5) Tasa de } \\
\text { pérdida de hábitats } \\
\text { reducida al menos a la } \\
\text { mitad }\end{array}$ & & & & & & & \\
\hline $\begin{array}{l}\text { 6) Pesquerías } \\
\text { gestionadas de manera } \\
\text { sostenible }\end{array}$ & & & & & & & \\
\hline $\begin{array}{l}\text { 7) Agricultura, } \\
\text { acuicultura y } \\
\text { silvicultura } \\
\text { sostenibles }\end{array}$ & & & & & & & \\
\hline $\begin{array}{l}\text { 8) Contaminaci } \\
\text { ón en niveles no } \\
\text { perjudiciales }\end{array}$ & & & & & & & \\
\hline $\begin{array}{l}\text { 9) Especies } \\
\text { exóticas, invasoras } \\
\text { controladas }\end{array}$ & & & & & & & \\
\hline $\begin{array}{l}\text { 10) Presiones } \\
\text { sobre ecosistemas } \\
\text { vulnerables son } \\
\text { minimizadas }\end{array}$ & & & & & & & \\
\hline $\begin{array}{l}\text { 11) Áreas } \\
\text { protegidas }(17 \%, 10 \%) \\
\text { eficaz }\end{array}$ & & & & & & & \\
\hline $\begin{array}{l}12 \text { ) Extinciones } \\
\text { evitadas, estado } \\
\text { mejorado (llega a } \\
30 \% \text { ) }\end{array}$ & & & & & & & \\
\hline $\begin{array}{l}\text { 13) Diversidad } \\
\text { genética mantenida }\end{array}$ & & & & & & & \\
\hline $\begin{array}{l}\text { 14) Servicios } \\
\text { ecosistémicos } \\
\text { esenciales restaurados }\end{array}$ & & & & & & & \\
\hline $\begin{array}{l}\text { 15) Resiliencia } \\
\text { incrementada, }\end{array}$ & & & & & & & \\
\hline
\end{tabular}




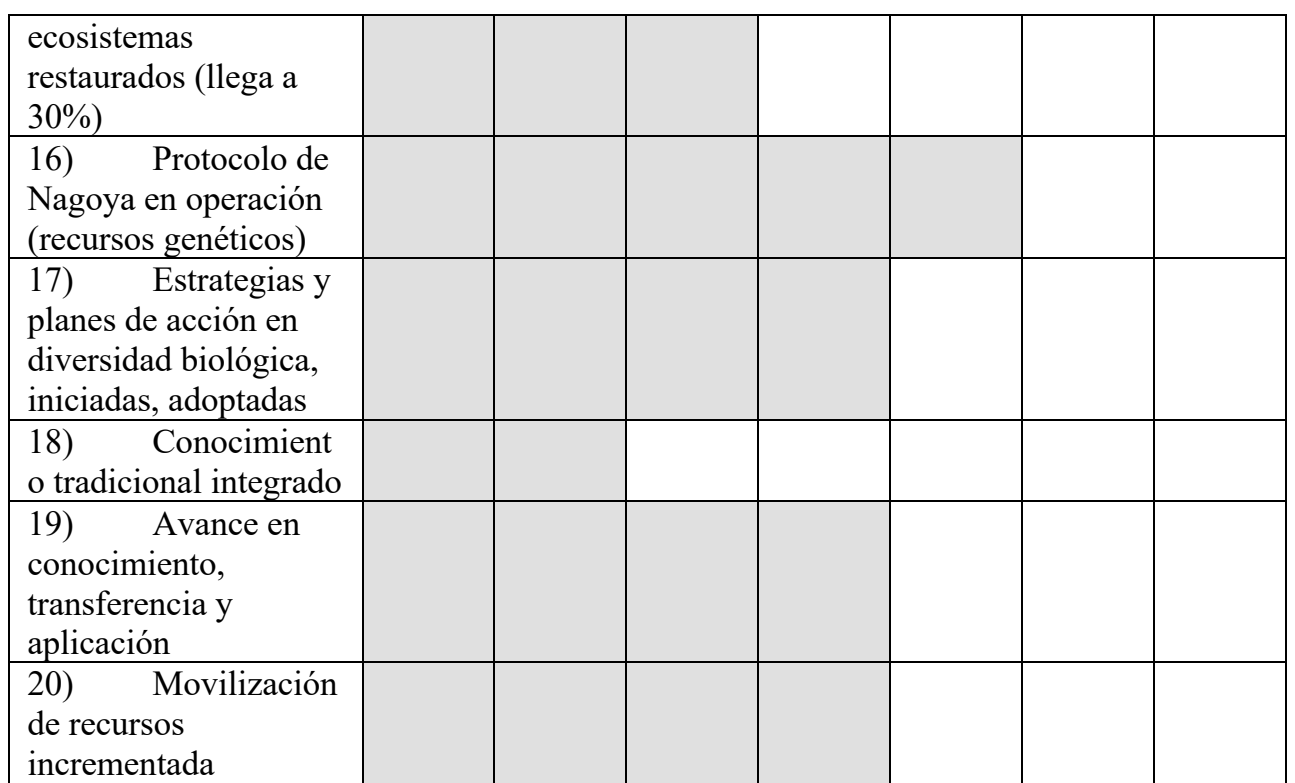

Fuente: MINAE, 2018. 